\title{
EL TAWANTINSUYU EN ALLAQMARCA, CARAYBAMBA, PROVINCIA DE AYMARAES, APURÍMAC
}

\author{
PIETER VAN DALen LUNA ${ }^{1}$ \\ UNIVERSIDAD NACIONAL MAYOR DE SAN MARCOS \\ pvandalen2@hotmail.com \\ HANS GRADOS RODRÍGUEZ ${ }^{2}$ \\ UNIVERSIDAD NACIONAL MAYOR DE SAN MARCOS \\ hans_231@hotmail.com
}

\section{RESUMEN}

El estado del Tawantinsuyu llegó a abarcar en su máxima expansión, casi todo el territorio de la Cordillera de los Andes. Para lograr esta magnífica expansión tuvo que absorber a las diferentes entidades socio políticas que ocupaban los Andes en sus diferentes latitudes. Esta situación fue posible gracias a la aplicación de una serie de estrategias políticas de dominación, aplicadas según la realidad socio cultural de cada una. El territorio de la nación Aymaraes (del Intermedio Tardío) no fue una excepción. Tras la anexión de los Aymaraes, se edificaron nuevos asentamientos de control Tawantinsuyu y se re-ocuparon otros antiguos fundados por los Aymaraes.

Palabras Claves: Arqueología, Apurímac, Aymaraes, Tawantinsuyu, Allaqmarca, Caraybamba.

\section{AbSTRACT}

The state of Tawantinsuyu got to include in its maximum expansion, almost the entire territory of the Andes. To achieve this magnificent expansion had to absorb the different sociopolitical entities occupying the Andes at different latitudes. This situation was made possible by implementing a series of political domination strategies, applied according to the socio cultural reality of each. The territory of the nation

1 Director del Proyecto de Investigación Arqueológica Allaqmarca. Arqueólogo y Educador. Docente EAP de Arqueología, Facultad de Ciencias Sociales, Universidad Nacional Mayor de San Marcos. Director del Museo de Arqueología y Antropología de San Marcos.

2 Jefe de campo del Proyecto de Investigación Arqueológica Allaqmarca. Arqueólogo. Universidad Nacional Mayor de San Marcos. 
Aymaraes (Late Intermediate) was no exception. After the annexation of Aymaraes, new settlements built Tawantinsuyu control and other ancient founded by Aymaraes be reoccupied.

KEYwords: Arqueología, Apurímac, Aymaraes, Tawantinsuyu, Allaqmarca, Caraybamba.

\section{INTRODUCCIÓN}

El presente artículo está referido a las características de la ocupación Tawantinsuyu en Allaqmarca en Caraybamba, a partir de los resultados obtenidos de las investigaciones con excavación desarrolladas en la primera mitad del año 2013 en el sitio arqueológico de Allaqmarca, ubicado en el distrito de Caraybamba, provincia de Aymaraes, región Apurímac. Las excavaciones en los tres sectores que conforman el asentamiento tuvieron el objetivo de definir las características de las ocupaciones del mismo. Se excavó al interior de edificacionesde datación tardía, principalmente del Tawantinsuyu, identificando áreas de función residencial, hallándose numerosos objetos personales suntuosos. En anteriores trabajos (van Dalen; 2007, 2009, 2011) hemos definido las características culturales prehispánicas del distrito de Caraybamba, analizando la interacción entre Allaqmarca y otros sitios cercanos como Marcapata, Wishcashuta, Pucarqasa o el mismo Apumarca.

\section{EL TAWANTINSUYU EN AYMARAES}

Los Incas aplicaron diferentes estrategias de dominación para cada región que conquistaban, según las condiciones de la misma. En las campañas de conquista, por tradición desde los primeros incas, se trataba de evitar el conflicto y batalla con las naciones que iban a ser sojuzgadas, mostrando al soberano con una actitud paternalista, misericordioso y clemente, presentándose como Hijo del sol. Actuaban activamente los embajadores que trataban de persuadir a los curacas de su rendición y acatamiento de las normas imperiales, tras lo cual recibían innumerables regalos en bienes y alimentos. En caso de no acatar las invitaciones de rendición, eran violentamente desaforados, y su población sobreviviente trasladada a otros lugares como mitqmas.

Aproximadamente hacia el año 1430 d. c. los incas que se encontraban de paso en la región persiguiendo a los Chancas que se encontraban en fuga por diferentes lugares tras ser derrotados en el Cusco, ocuparon la región, mediante rápidas y violentas incursiones, dando como resultado la anexión del territorio al Tahuantinsuyu. Casi todos los cronistas señalan esto, salvo el Inca Garcilazo de la Vega, quien señala en el capítulo X, de su libro Tercero, de los Comentarios Reales de Los Incas, que fue el inca Cápac Yupanqui (quinto inca), quien conquistó a la nación Aymaraes. El territorio de Caraybamba fue conocido en la colonia como la parcialidad de Cayao Aymara, al igual que Colca, Cotaruri y Pampamarca. Garcilazo narra como se dio la anexión de estos territorios al Tawantinsuyu. Garcilaso señala lo siguiente:

"El quinto capitan, Auqui Topa Inga Yupanqui, fue hijo de Capac Yupanqui, fue valeroso capitan, que mato muy muchos indios y capitanes y principales; a sus enemigos cortaba las cabezas para los presentar a su padre Capac Yupanqui Inga, para que los viese y se holgase de la victoria de su hijo; y conquisto las provincias de los Quichiuas, Aymara, Uaquirca, Collana, Taypi Aymara, Yanaca, Cayau Aymara, Challuanca, Pampamarca, todo el rio abajo, y los demas sus hermanos Inti Auqui Inga, Yupanqui Inga, Illapa Tupa Inga, todos los dichos se murieron sin conquistar en el Cuzco.

El Inca salió del Cozco y llevó casi veinte mil hombres de guerra; llegó a la puente que esta ocho leguas de la ciudad, ${ }^{3}$ camino bien áspero y dificultoso, que solamente la cuesta que hay para baxar al rio tiene, de baxada, grandes tres leguas, casi perpendicularmente, que por el altura no tiene media legua, y de la subida de la otra parte del rio tiene otras tres leguas. Passando la puente, entró 
por una hermosa provincia llamada Yanahuara, que hoy tiene mas de treinta pueblos; los que entonces tenia no se sabe, mas de que el primer pueblo que hay por aquella vanda se dize Piti, salio con todos sus moradores, hombres y mujeres, viejos y niños, con gran fiesta y regozijo, con grandes cantares y aclamaciones al Inca, y lo recibieron por señor y le dieron la obediencia y vasallaje. El Inca los recibio con mucho aplauso y les dio muchas dadivas de ropas y otras cosas que en su corte se usavan traer. Los del pueblo Piti enviaron mensajeros a los demas pueblos de su comarca, que son de la misma nación Yanahuara, avisandoles de la venida del Inca y como lo havian recebido por Rey y señor, a cuyo ejemplo vinieron los demas curacas, y con much a fiesta hizieron lo mismo que los de Piti.

El Inca los recibio como a los primeros y les hizo mercedes y regalos, y para mayor favor quiso ver sus pueblos y pasearlos todos, que estan en espacio de veinte leguas de largo y mas de quince de ancho. De la provincia Yanahuara passó a otra llamada Aimara. Entre estas dos provincias hay un despoblado de quinze leguas de travessia. De la otra parte del despoblado, en un gran cerro que llaman Mucansa, hallo gran numero de gente recogida para resistirle el passo y la entrada de su provincia, que tiene mas de treinta leguas de largo y mas quinze de ancho, ricas de minas de oro y plata y plomo y de mucho ganado, poblada de mucha gente, la cual antes de la reduccion de los pueblos tenia mas de ochenta.

El Inca mandó aloxar su exercito al pie del cerro para atajar el passo a los contrarios, que, como gente barbara, sin milicia, havian desamparado sus pueblos y recogidose en aquel cerro por lugar fuerte, sin mirar que quedavan atajados como en un corral. El Inca estuvo muchos dias sin quererles dar batalla ni consentir que les hiciesen otro mal mas de prohibirles los bastimentos que podian haver, porque forcados de el hambre se rindiessen, y por otra parte les convidava con la paz.

En esta porfia estuvieron los unos y los otros por mas de un mes, hasta que los indios rebeldes, necesitados de el hambre, enviaron mensajeros al Inca, diziendo que ellos estavan prestos y aparejados de recebirle por su Rey y adorarle por hijo del sol, si como tal hijo del sol les dava su fe y palabra de conquistar y sujetar a su imperio (luego que ellos se huviessen rendido) la provincia Umasuyu, vezina a ellos, poblada de gente belicosa y tirana, que les entravan a comer sus pastos hasta las puertas de sus casas y les hazian otras molestias, sobre lo cual havian tenido guerras con muertes y robos, las cuales aunque se havian apaciguado muchas vezes, se havian buelto a encender otras tantas, y siempre por la tirania y desafueros de los de Umasuyu; que le suplicavan, pues havian de ser sus vasallos, les quitasse aquellos malos enemigos, y que con esta condición se le rendían y le recebian por Principe y señor.

El Inca respondio por un capitan que el no havia venido alli sino a quitar sinrazones y agravios y a enseñar a todas aquellas naciones barbaras a que viviesen en ley de hombres y no de bestias, y a mostrarles el conocimiento de su Dios el Sol, y pues el quitar agravios y poner en razon los indios era oficio del Inca, no tenian para que ponerle por condicion lo que el Rey estaba obligado a hazer de oficio; que les recebia el vasallaje, mas no la condicion, porque no le havian ellos de dar leyes, sino recebillas del hijo del sol; que lo que tocava a sus disensiones, pendencias y guerras, lo dexassen a la voluntad del Inca, que el sabia lo que havía de hazer.

Con esta respuesta se bolvieron los embaxadores, y el dia siguiente vinieron todos los indios que estaban retirados en aquellas sierras, que eran mas de doze mil hombres de guerra; truxeron consigo sus mujeres e hijos, que passavan de treinta mil animas, las cuales todas venian en sus cuadrillas, divididas de por si la gente de cada pueblo y, puestos de rodillas a su usanza, acataron al Inca y se entregaron por sus vassallos, y, en señal de vasallaje, le presentaron oro y plata y plomo $y$ todo lo demas que tenian. El Inca los recibio con mucha clemencia, y mando que les diessen de comer, que venian traspasados de hambre, y les proveyesen de bastimentos hasta que llegasen a sus pueblos, por que no padeciesen por los caminos, y mandoles que se fuesen luego a sus casas.

Despachada la gente, se fue el Inca a un pueblo de los de la misma provincia Aimara, llamado Huquirca, que hoy tiene mas de dos mil casas, de donde embio mensajeros a los caciques de Umasuyu." (Inca Garcilazo de la Vega 1609: Libro tercero, Capítulo X). 
Luego de conquistar una nación, los Incas procedían a metrar el territorio y a dividir las tierras, según la productividad, designando las tierras para el sol, para el Inca y para la población local. Para ello necesitaban extender y ampliar las áreas cultivables, construyendo amplios sistemas de andenerías, incluso aprovechando terrenos totalmente inaccesibles y de gran pendiente. Previamente edificaban grandes extensiones y ramificaciones de acequias y canales de regadío.

La economía Inca fue políticamente organizada. La actividad económica más importante fue la agricultura intensiva, en el cual los factores de producción eran controlados por el estado. La producción se realizaba con tres fines: para el consumo propio, para la comunidad (ayllu) y para el estado. La circulación de divisas se realizó gracias al permiso del poder imperial y por decisiones administrativas. En la agricultura se utilizaron una gran variedad de técnicas, según las características de las mismas, la altitud y la región en que se encontraba, modelando el terreno mediante una gran variedad de canales de irrigación, chacras hundidas, aterrazamientos, sistemas de andenerías, entre otros. Sin embargo, muchas de estas obras no fueron construidas propiamente por los incas, ellos ya las encontraron al conquistar las diversas regiones, utilizándolo para un mejor control del estado. La agricultura se ejecutó con herramientas rudimentarias, dando sorprendentes resultados. Por otra parte la forma de organización laboral fue basada en la clasificación de la población en base al sistema numérico decimal, la edad de los trabajadores y su unidad territorial o social. Tanto en la agricultura como en la elaboración de artículos artesanales, la unidad básica de producción la constituyó la unidad familiar comunal o el ayllu. Estas unidades estaban bajo manejo de administradores menores dentro de cada ayllu. Es de gran importancia señalar que la misma organización para las labores comunales, podían ser usadas para el intercambio de labores entre unidades familiares entre el mismo ayllu, para trabajos comunales y para trabajos públicos a favor del estado.

La economía del Tawantinsuyu fue básicamente una economía natural, en el cual todas las transacciones fueron desarrolladas entre especies que iban a satisfacer directamente las necesidades primordiales. Así la producción fue orientada directamente al uso. La actividad mercantil no estaba dentro de la organización de la producción; el mantenimiento de la clase dominante y del estado y su sistema de ingresos estaba basado en demandas de trabajo y bienes. Se dio un predominio de una economía controlada por la estructura política.

La acumulación de excedente económico fue realizada debido a las prestaciones de los ayllus y la apropiación del estado del producto de las unidades económicas estatales. El excedente económico fue utilizado para el mantenimiento y sostén de la clase dominante y para la ejecución de obras públicas de interés general. El excedente productivo de propiedad del estado era utilizado en la redistribución, en la realización de obras públicas y en las ceremonias religiosas. Una parte del excedente lo constituyeron aquellos bienes de lujo y suntuarios reservados para las clases dominantes y para el uso ceremonial en actividades religiosas. Las ceremonias religiosas fueron ocasiones para la redistribución de bienes como vestidos, joyas y otros regalos; el consumo de grandes cantidades de alimentos y bebidas; e incluso la destrucción mediante el sacrificio, de bienes y recursos que representaban parte del excedente económico productivo.

En el caso de Caraybamba, ubicado dentro de la provincia inca de Aymaraes, los Incas buscaron aprovechar al máximo las tierras con fines agrícolas, ampliando los andenes de Caraybamba y Colca, edificando nuevas graderías de andenes del tipo "muro y relleno" (andenes convencionales imperiales) en áreas de gran erosión y pendiente, y refaccionado muchos de los edificados por los aymaraes. Así, el canal que proviene de Wishcashuta dataría de este periodo, al igual que los otros importantes que discurren por entre este sistema de andenerías. Así, la estrategia de dominación Inca en Caraybamba denota el control de las áreas agrícolas productivas, como andenes y canales de irrigación.

Por otra parte algunos ayllus locales habrían sido trasladados hacia otras regiones del imperio en calidad de mitqmas, para realizar servicios a favor del estado y actuar como administradores en las guarniciones militares; así como también llegaron a Caraybamba desde otras regiones para realizar las mismas funciones. Los mitqmas que eran trasladados por los incas de un lugar a otro, por lo general eran llevados a regiones con las mismas características orográficas y climáticas del que provenían. 
Los mitqmas que llegaron a Aymaraes, habrían sido ayllus de origen quechua, posiblemente traídos desde Ayacucho o la sierra central, los cuales se constituirían años mas tarde, ya en la época colonial, en la parcialidad "Quichuas", referida en la visita de 1574 del virrey Francisco de Toledo a la región.

El Tahuantinsuyu edificó asentamientos de control en medio del sistema de andenerías, entre estos Wishkashuta, que habría sido ocupado por mitqmas, con la finalidad de trabajar y administrar la producción del inca y el sol; mientras que ocuparon otros sitios preexistentes, caso Allaqmarca, introduciendo nuevas estructuras de planta rectangular después de refaccionar los andenes, asentándolos sobre las terrazas, con una arquitectura tipo inca local, no muy finamente elaborada, con vanos trapezoidales de una sola jamba, pero demostrando con sus bloques pétreos y técnica constructiva el poder imperial supremo.

La mayoría de asentamientos Aymaraes del Intermedio Tardío, continuaron siendo ocupados durante el imperio del Tahuantinsuyu, notándose la continuidad del desarrollo cultural, aunque con variaciones significativas. Se nota la construcción de estructuras rectangulares, posiblemente con fines de control, especialmente en aquellos sitios ubicados en áreas estratégicas (Pucarqasa y Qushku). La técnica constructiva de las edificaciones del Tahuantinsuyu, presenta piedras canteadas de formas mas definidas, mampuestas con argamasa, formando hileras mas uniformes y en algunos casos con enlucidos de barro.

Durante los años de guerra civil entre Huascar y Atahualpa, el territorio Aymaraes y en sí todo el departamento de Apurímac fue escenario de numerosos enfrentamientos. Así el padre Bernabé Cobo en su crónica Historia del Nuevo Mundo menciona:

"Estando Atahualpa con sus huestes avanzando sobre el Cuzco, a la captura de la ciudad, libró muchas batallas con las fuerzas de Huascar que resistían los constantes ataques, siendo dos de estas, una en Aymaraes y la otra entre Curaguasi y Avancay, batallas muy sangrientas donde murieron muchos soldados de ambos ejércitos, donde salió victorioso Atahualpa, retirándose las fuerzas de Huascar al Cuzco. "

(Cobo 1653: Libro 12, Capítulo XVIII,).

\section{UBICACIÓN DEL SITIO DE ALLAQMARCA}

El sitio arqueológico de Allaqmarca se encuentra ubicado en el valle medio - bajo del río Caraybamba, en la margen derecha, distrito de Caraybamba, provincia de Aymaraes. La ubicación delacota en la parte media del sitio se ubica en las coordenadas UTM:(WGS-84): 8410662 N, 698667 E, y a 3300 m.s.n.m. Se accede al sitio por un sendero que atraviesa los campos de cultivo, desde el puente Aparaya, por la margen derecha del río Caraybamba, en dirección sur hacia el cerro Allaqmarca.

El río Caraybamba, es un río perteneciente a la vertiente del Amazonas, ubicado en el departamento de Apurímac, provincia de Aymaraes. En su confluencia con el río Cotaruse, que se desplaza en la margen izquierda en dirección Sur - Oeste a Nor Este, forman el río Chalhuanca, afluente a su vez del río Antabamba por la margen izquierda.

La cuenca del río Caraybamba está conformado por numerosos afluentes, que se ramifican encañonadamente en los contrafuertes mas elevados de la provincia de Antabamba, originándose a partir de los desagües de pequeñas lagunas de origen glaciar, a mas de 4800 metros sobre el nivel del mar. El afluente de mas lejano origen es el río Qalachaca, que recibe las aguas de la quebrada Inque por la margen derecha y las quebradas de Tambo y Huayllaqalluc, por la margen izquierda. 


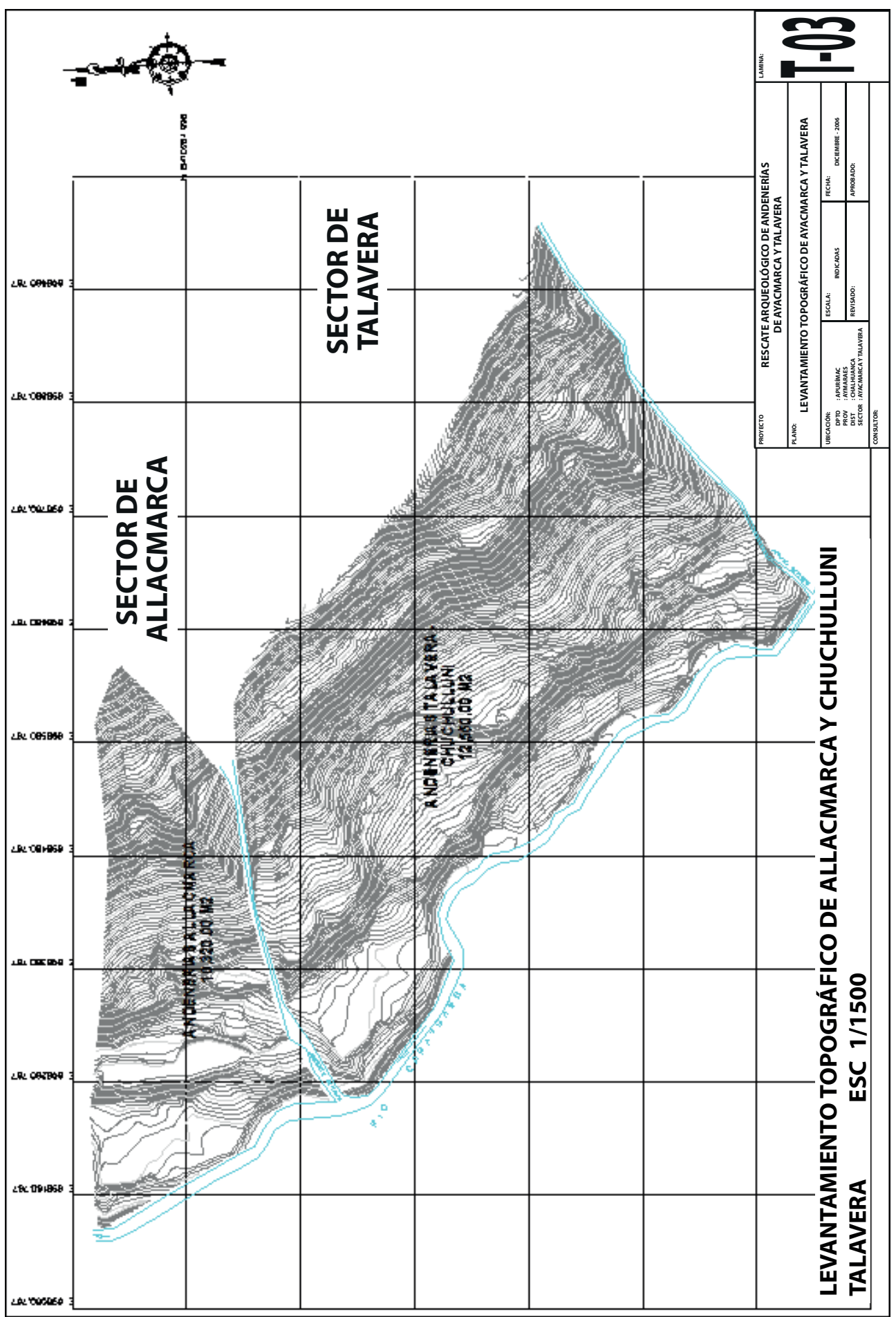

Figura 2: Plano topográfico de los sectores de andenes de Allaqmarca y Chuchulluni-Talavera. 


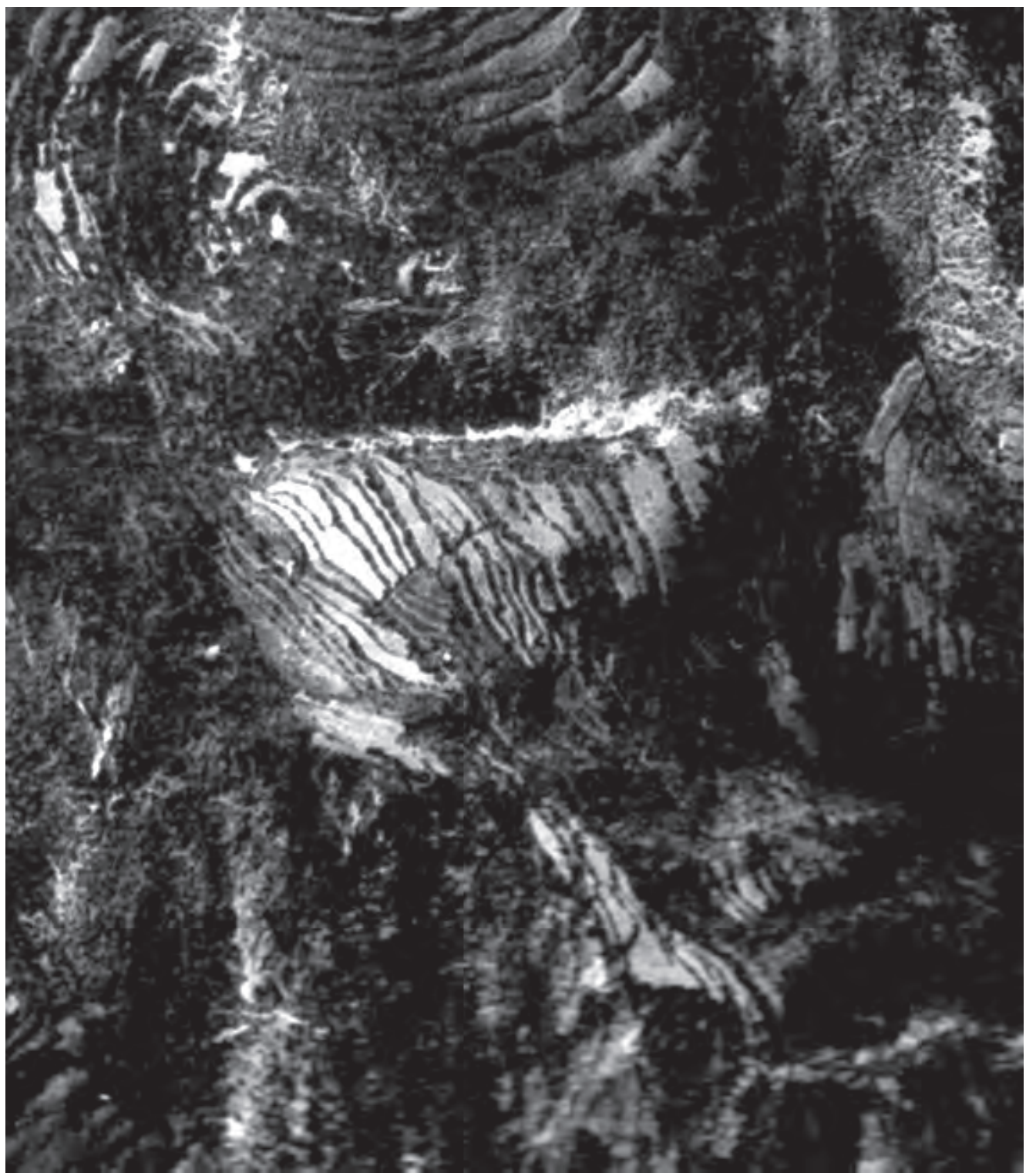

Figura 3: Foto aérea mostrando el cerro Allaqmarca con sus andenerías, de imponente forma piramidal.

\section{DESCRIPCIÓN DE LOS COMPONENTES DEL SITIO ALLAQMARCA}

El sitio se ubica en medio del extenso y complejo sistema de andenerías de Caraybamba, de grandes extensiones, llegando a tener un largo de hasta $16 \mathrm{Kms}$. Presenta diferentes sectores naturales: Aparalla - Occoñe, Allaqmarca, Chuchulluni - Talavera, Jasccechu - Tahuatu, Wishcashuta, Campilla - Ccaccalla, Fuiza, entre otros, ubicados en ambas márgenes del río. En este caso el asentamiento se emplaza sobre el sector Allaqmarca. El sector Allaqmarca se encuentra ubicado justo frente al pueblo mismo de Caraybamba y se caracteriza por emplazarse sobre un cerro de imponente forma piramidal. Los andenes se extienden desde la misma orilla del río, con graderías de hasta 4 metros de 

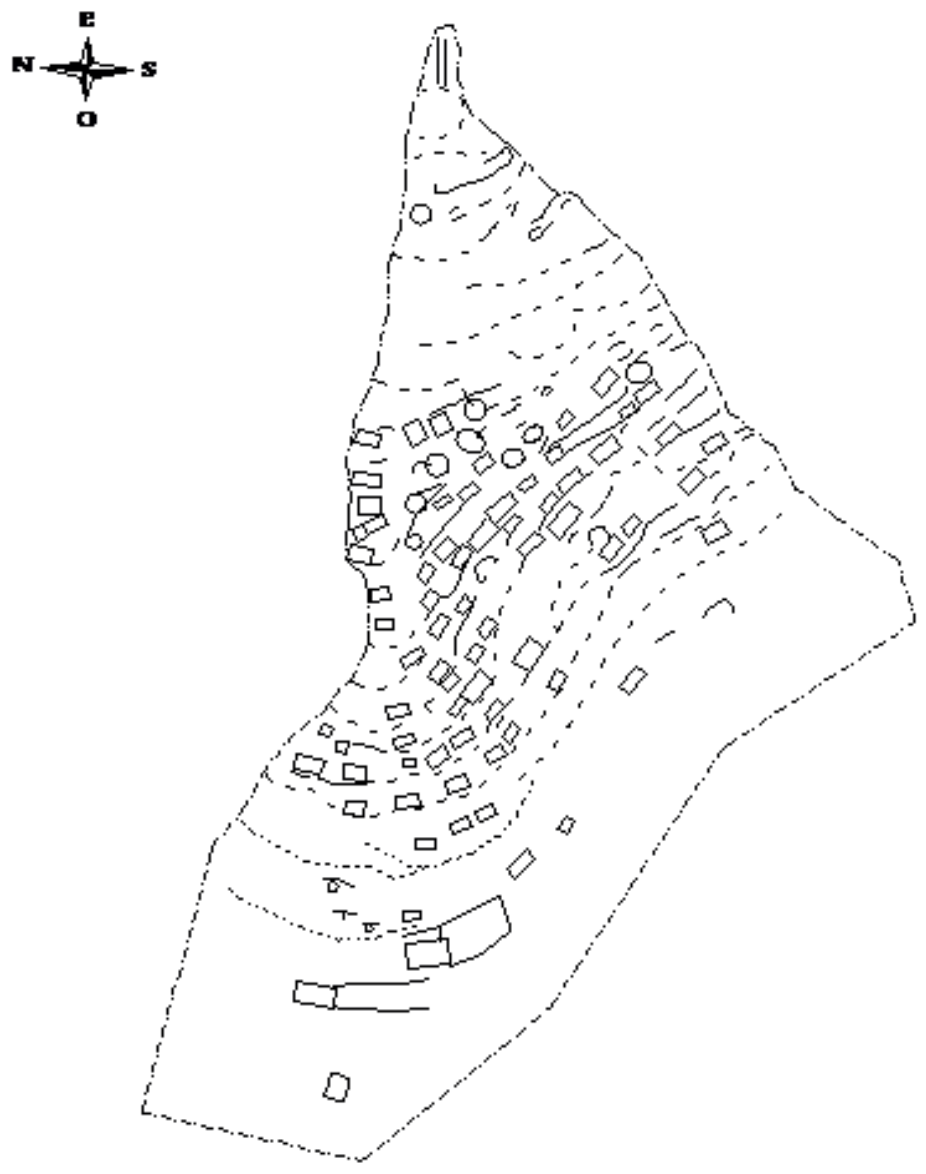

\begin{tabular}{|c|c|c|}
\hline \multicolumn{3}{|c|}{ REGISTROS DE SITIOS ARQUEOLÓGICOS DEL DISTTITO DE } \\
CARYBAMBA-COLCA \\
\hline REGIÓN & APURIMAC & LAMINA \\
\hline PROVINCIA & AYMARAES & \\
\hline DISTRITO & CARAYBAMBA \\
\hline COMUNIDAD & CARYBAMBA \\
\hline SITIO & ALLAJMARCA & \\
\hline
\end{tabular}

SDE.

Figura 4: Plano arquitectónico del sitio de Allaqmarca.

altura, extendiéndose hasta la parte superior del mismo cerro. En la tercera parte superior presenta un asentamiento tardío. Este sector tiene un área aprox. de 10 Has. El cerro Allaqmarca se encuentra delimitado por el Norte con el sector de andenerías Uquñi, mediante una quebrada llamada Uquñi, mientras que por el Sur se delimita del sector Chuchulluni mediante la quebrada Allaqmarca. Estos dos riachuelos son fuente de numerosas especies, que conjuntamente con el río mismo de Caraybamba se habrían conformado en una de las despensas alimenticias del antiguo poblador caraybambino.

El sitio arqueológico de Allaqmarca está conformado por un conjunto de recintos de planta semicircular y rectangular, de dimensiones variadas, con el vano orientado hacia el sur, interconectados entre sí por pasadizos que ascienden zigzageantes hacia las partes mas elevadas del asentamiento, según la topografía del terreno. Se aprecia en superficie abundante material cerámico de estilos Inca Imperial, Inca Local y del Intermedio Tardío. Además en el interior de los recintos se aprecian batanes y manos de moler. 
Tres recintos por su buen estado de conservación permiten obtener la altura original de la contracción, la forma de vano y su acabado. Los recintos tienen 9 metros de largo por 5 metros de ancho con una elevación promedia de 2.50 metros. Los recintos son de una sola pieza y sin hastíales dado que la altura de los muros que forman la caja rectangular es uniforme. Posiblemente la cubierta fue de cuatro aguas apoyada sobre la parte superior de los muros. La armadura de viguetas entrelazadas con ramas, luego cubiertas con ichu aparece como una de las formas mas frecuentes de la cubierta Inka. A 1.5 metros de la superficie aparece una hilera de nichitos de forma trapezoidal con medidas muy irregulares que van de los $0.5 \mathrm{~m}$. por lado hasta $0.2 \mathrm{~m}$. su acceso es de forma trapezoidal de 1.10 metros de ancho en la base con $0.90 \mathrm{~m}$ en la parte superior y una altura de 1.90 metros.

Resalta la presencia de una iglesia colonial construido en la parte inferior del lado Oeste del sitio. La Iglesia colonial de 13 metros de largo por 5 metros de ancho con muros de 3 metros alto con ancho promedio de 1 metro. Sobre el muro Oeste aparece una ventana de forma trapezoidal tanto en la elevación como en la planta. Su acceso tiene 2 metros de ancho. Conserva el hastial del lado lateral Norte que llega hasta 6 metros de alto tomado desde la superficie. Las calles, pasajes y corredores son estrechos y por lo general se presentan en forma zigzagueante en función de la topografía.

El sitio está flanqueado por acantilados naturales que dan a riachuelos ubicados en sus extremos Norte, Sur y Este. Cerca o en medio de los acantilados se construyeron Chullpas de uno y dos niveles, en áreas casi inaccesibles por su elevada pendiente y verticalidad. Lamentablemente muchos de estos se encuentran disturbados. De igual manera en la parte superior del cerro se aprecian también matrices de forma ovalada, correspondiente a contextos funerarios; así como una pequeña chullpa de planta rectangular y una altura de 0.60 metros.

Para la construcción de las Chullpas perforaron los acantilados y sellaron el acceso con piedras planas unidas con mortero de barro. El acceso es restringido y tiene forma rectangular. No hay evidencia de pintura, solo se conserva pequeñas evidencias de enlucido hacha con arcilla de color amarillo rojizo. El interior de las Chullpas está vacío o muy disturbado con escasa presencia de pequeños fragmentos de restos óseos.

El sitio pertenece al Periodo Intermedio Tardío, Horizonte Tardío y Colonial. La organización del espacio y la presencia de elementos arquitectónicos tales como los recintos semi circular, rectangular, las Chullpas y la Iglesia, nos indican que el sitio tuvo una ocupación continua en estos periodos.

Durante el Intermedio Tardío, el sitio habría sido ocupado por los Aymaraes quienes construyeron la mayoría de los andenes, Chullpas y los recintos de planta semi circular y las irregulares. La presencia Inka se reflejado en los recintos rectangulares con nichos y acceso trapezoidal y el mejor ordenamiento del espacio social y agrícola. Los españoles se asentaron en el sitio durante los primeros años de ocupación colonial. Su presencia se ve reflejada a través de la iglesia. No hay cambios notorios en el sistema de organización espacial del sitio.

El sitio presenta tres sectores: El sector A, ubicado en la parte superior; el sector B, ubicado en la sección media del cerro Allaqmarca, en los alrededores de la iglesia; y el sector C, conformado por el sistema de andenerías circundante. El sitio de Allaqmarca tiene 20 Has. aprox., con sectores de vivienda, funerarios, administrativos y residenciales.

El sitio de Allaqmarca presenta aflorante una arquitectura, conformando recintos de planta rectangular (aproximadamente unos 40) y unos 8 de forma irregular, asociados a calles y pasadizos que ascienden zigzageantes hacia las partes más elevadas del asentamiento. Los materiales de construcción son: piedra canteada, canto rodado y argamasa con barro con inclusiones de pequeñas piedras. Las técnicas de construcción son muros de piedras mampuestas con argamasa. La cerámica que se observa en la superficie es del estilo Caraybamba (Intermedio tardío) Tawantinsuyu local y Tawantinsuyu imperial. 
El sector B de este sitio de Allaqmarca, ubicado en la parte media superior del sector de andenerías Allaqmarca fue el área nuclear del asentamiento de control Tawantinsuyu, encargado de ordenar, dirigir y regular los trabajos de edificación de los andenes y luego los trabajos agrícolas a desarrollarse en el mismo. Posteriormente a la llegada de los españoles, en un primer momento, siguieron poblando este sitio, ya que en la parte baja del sector B se ubica una edificación Tawantinsuyu, reacondicionado en los periodos colonial temprano, para funcionar como la primera iglesia matriz de Caraybamba. Posteriormente, este al igual que otros pueblos del área, fueron reducidos al pueblo actual de Caraybamba, hoy capital del distrito.

\section{LAS EXCAVACIONES ARQUEOLÓGICAS EN ALLAQMARCA- TEMPORADA 2013}

Entre los meses de febrero y abril del año 2013 se desarrollaron trabajos de investigación, con la excavación de 12 unidades de 4x4 metros, dispuestas al interior de algunos recintos, en medio de patios o sobre las terrazas que conforman este sector de andenerías de Allaqmarca. La secuencia estratigráfica identificada en estas unidades fue la siguiente:

1.- Excavaciones en el sector A: En el sector A o sector superior se realizó la excavación de 3 unidades, las cuales fueron las siguientes:

UNIDAD 1: Se ubica en la parte más alta del sitio arqueológico, emplazada sobre un promontorio rocoso, el cual mediante un sistema de aterrazamiento dio horizontalidad al terreno. La unidad se ubicó en el interior del recinto semi circular de $3.60 \mathrm{~m}$ de diámetro. La secuencia estratigráfica identificada es la siguiente:

Capa superficial: Conformada por vegetación y tierra de color negro. Es irregular y continua, tiene una inclinación de norte a sur. En superficie se halló fragmentos de cerámica doméstica. En la parte superior de la unidad se puede apreciar el paramento y parte de la cabecera de un muro semi circular, en mal estado de conservación.

Capa 1: Tierra de color negro de consistencia semi-compacta, piedras medianas, raíces de plantas y material cultural. La superficie de esta capa es irregular y continua, presenta un grosor máximo de $0.40 \mathrm{~m}$ y un mínimo de $0.15 \mathrm{~m}$. Al interior del recinto se halló fragmentos de cerámica local (engobe rojo y naranja), Tawantinsuyu imperial (motivos geométricos y diamantados), domestica (con hollín en gran parte del cuerpo). Hacia el exterior del recinto se identificó fragmentos de cerámica en menor cantidad de engobe rojo y naranja. También se halló material lítico (desperdicios de obsidiana y mano de batan fracturados); y óseo animal fracturado. En el interior de la capa se halló el maxilar inferior de un camélido (aun presenta dentadura), asociado a la matriz de un entierro que más tarde se haría visible, acompañado de una piedra circular cuyo diámetro es de $0.18 \mathrm{~m}$. Como parte del relleno se halló carbón en poca cantidad, se definió el muro del recinto y aun se podía observar el derrumbe parcial del paramento en un $10 \%$.

Capa 2: Tierra de color beige de consistencia semi-compacta, piedras pequeñas y medianas, raíces de plantas y material cultural. Presenta un grosor que varía de $0.20 \mathrm{~m}$ a $0.80 \mathrm{~m}$. En el interior del recinto se identificó fragmentos de cerámica local y cerámica Tawantinsuyu imperial (motivos geométricos). En esta capa se halló un contexto funerario secundario, cuya cista elaborada a base de piedras canteadas es de forma semi-circular es de $1.40 \mathrm{~m}$. de ancho y $0.95 \mathrm{~m}$. de largo e intrusiva a la capa, observándose los restos casi completos de hasta 7 individuos, entre ellos un individuo de sexo femenino de aprox. 18 años, dispuesto en posición extendido, casi completo que cubre a las osamentas dispersas, asociado a una vasija Tawantinsuyu local, un tupo y un batán de basalto; fuera de la matriz del entierro se hallaron morteros fracturados por la mitad.

Capa 3: Conformado por la roca geológica de color rojizo amarillento de consistencia compacta. 

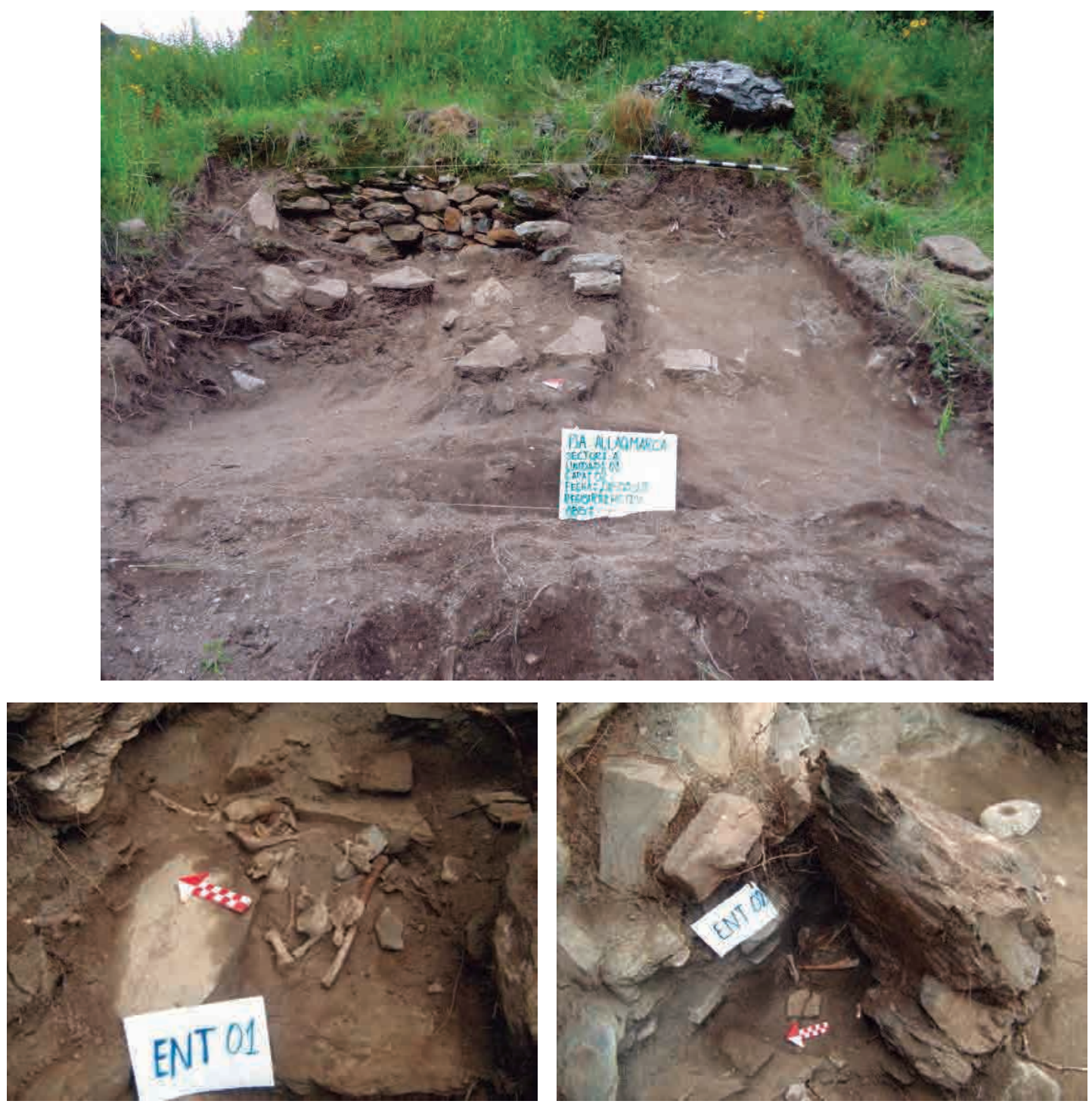

Figura 5 (Superior): Vista de la capa 2, unidad 1. Figuras 6 y 7 (Inferior izquierda y derecha): Vista de contextos funerarios de la unidad 1.

UNIDAD 2: Ubicado en la parte superior del asentamiento. La secuencia estratigráfica identificada es la siguiente:

Capa superficial: Capa de tierra color negro cubierta de vegetación, de $0.05 \mathrm{~m}$ a $0.08 \mathrm{~m}$ de grosor. En esta capa se halló fragmentos de cerámica del estilo Tawantinsuyu en su variante local, regional e imperial; también se tiene dos batanes y dos morteros.

Capa 1: Tierra de color negro de consistencia semi compacta, de un grosor promedio de $0.10 \mathrm{~m}$., conteniendo fragmentos de cerámica (en mayor cantidad del estilo Tawantinsuyu local), lascas de obsidiana, percutores, carbón disperso y una cornamenta de taruca. En esta capa ya se puede observar parte de la cabecera de un muro, que pertenecía a un recinto de planta ovalada, orientado al norte. 
Capa 2: Capa de arcilla de color rojizo de consistencia compacta, de un grosor promedio de $0.15 \mathrm{~m}$. En cuanto a los componentes culturales se puede mencionar: fragmentos de cerámica de estilo Caraybamba y Tawantinsuyu local (con engobe de colores: rojo naranja y negro); carbón de origen vegetal (abarcaba un $10 \%$ de la unidad), la presencia del hallazgo $\mathrm{N}^{\circ} 1$ (un cuchillo de basalto de 0.09 $\mathrm{m}$ de largo) y dos cistas que contenían contextos funerarios.

En esta capa se hicieron tres pozos de cateo de $1 \mathrm{~m}$ por $1 \mathrm{~m}$. En el primer cateo se halló una cantidad mínima de fragmentos de cerámica de engobe negro. En el segundo cateo se halló una cantidad mínima de fragmentos de cerámica local y unos cuantos fragmentos Tawantinsuyu local. El tercer cateo está asociado al muro del recinto semi circular y al muro de contención de la terraza, hallándose fragmentos de cerámica Caraybamba y Tawantinsuyu local en poca cantidad.

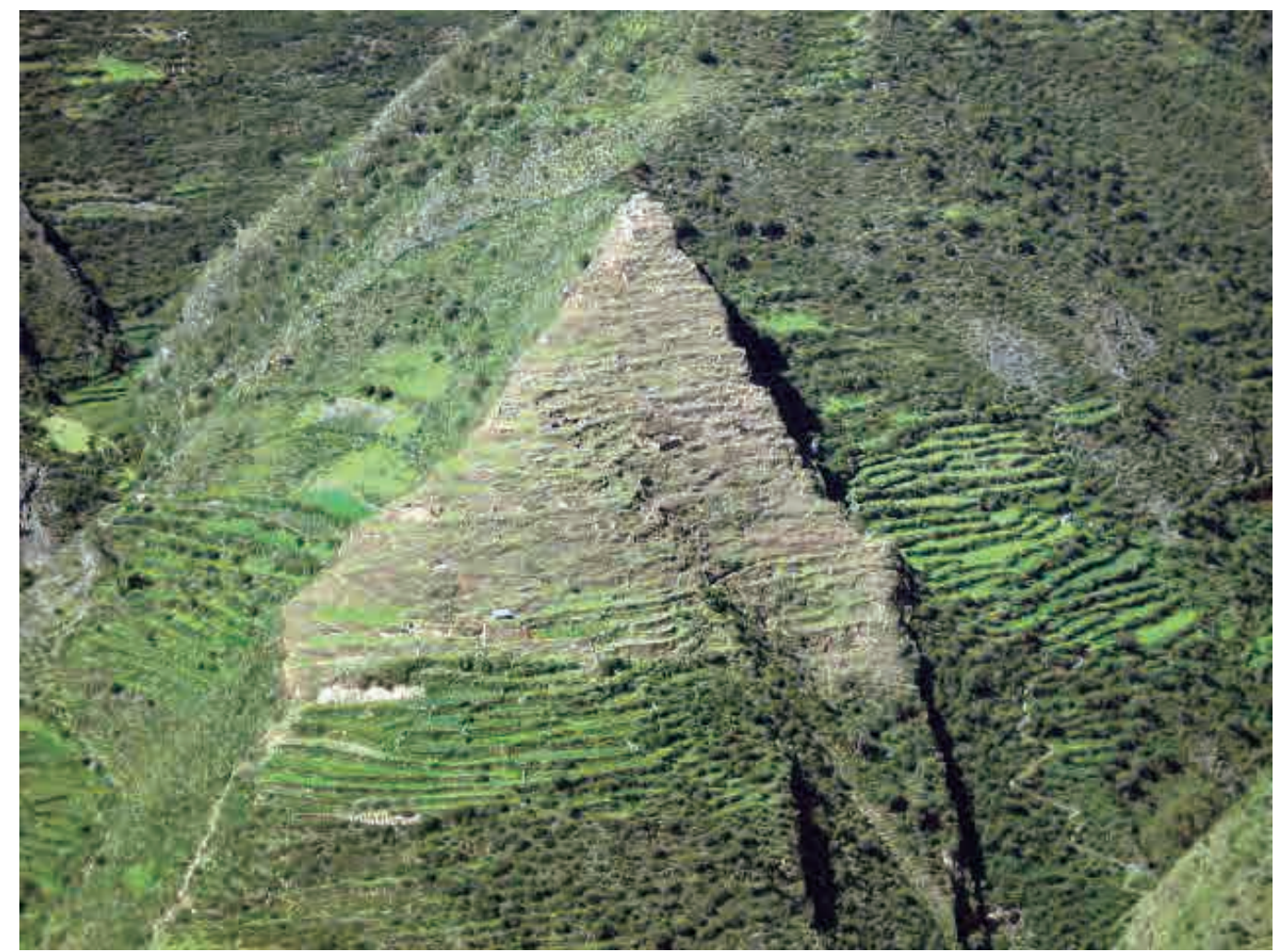

Figura 8: Vista panorámica del sector de andenerías de Allaqmarca, con el asentamiento en la parte superior.

Contexto funerario 1: Se encuentra intruyendo la capa 2, conformado por una estructura tipo cista de planta pentagonal, de $0.45 \mathrm{~m}$ de largo, una profundidad de $0.50 \mathrm{~m}$ y un ancho de $0.30 \mathrm{~m}$, elaborada en base a lajas de piedra adosadas sin argamasa, con piso conformado por una laja de piedra, sobre el cual se depositó el cuerpo del individuo. El individuo es un neonato de 7 a 8 meses de edad, hallándose disturbado.

Contexto funerario 2: Se ubicaba al sur-este de la unidad. La estructura funeraria está conformada por una pequeña cista de planta ovalada: de $0.32 \mathrm{~m}$ de diámetro y una profundidad de $0.50 \mathrm{~m}$, hallándose en su interior otro neonato, sin materiales asociados.

Capa final: Arcilla rojiza y la roca geológica del cerro de consistencia muy dura. 

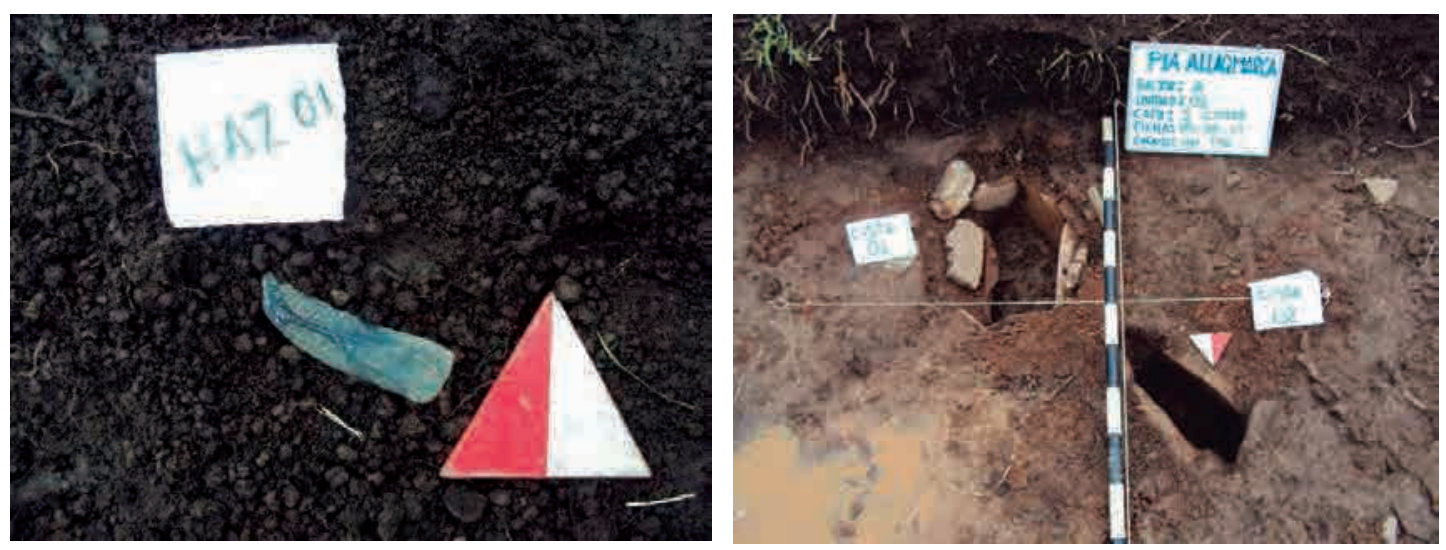

Figura 9 (Izquierda): Unidad 2, Hallazgo 1 (cuchillo). Figura 10 (derecha): Unidad 2, vistas de las dos cistas funerarias.

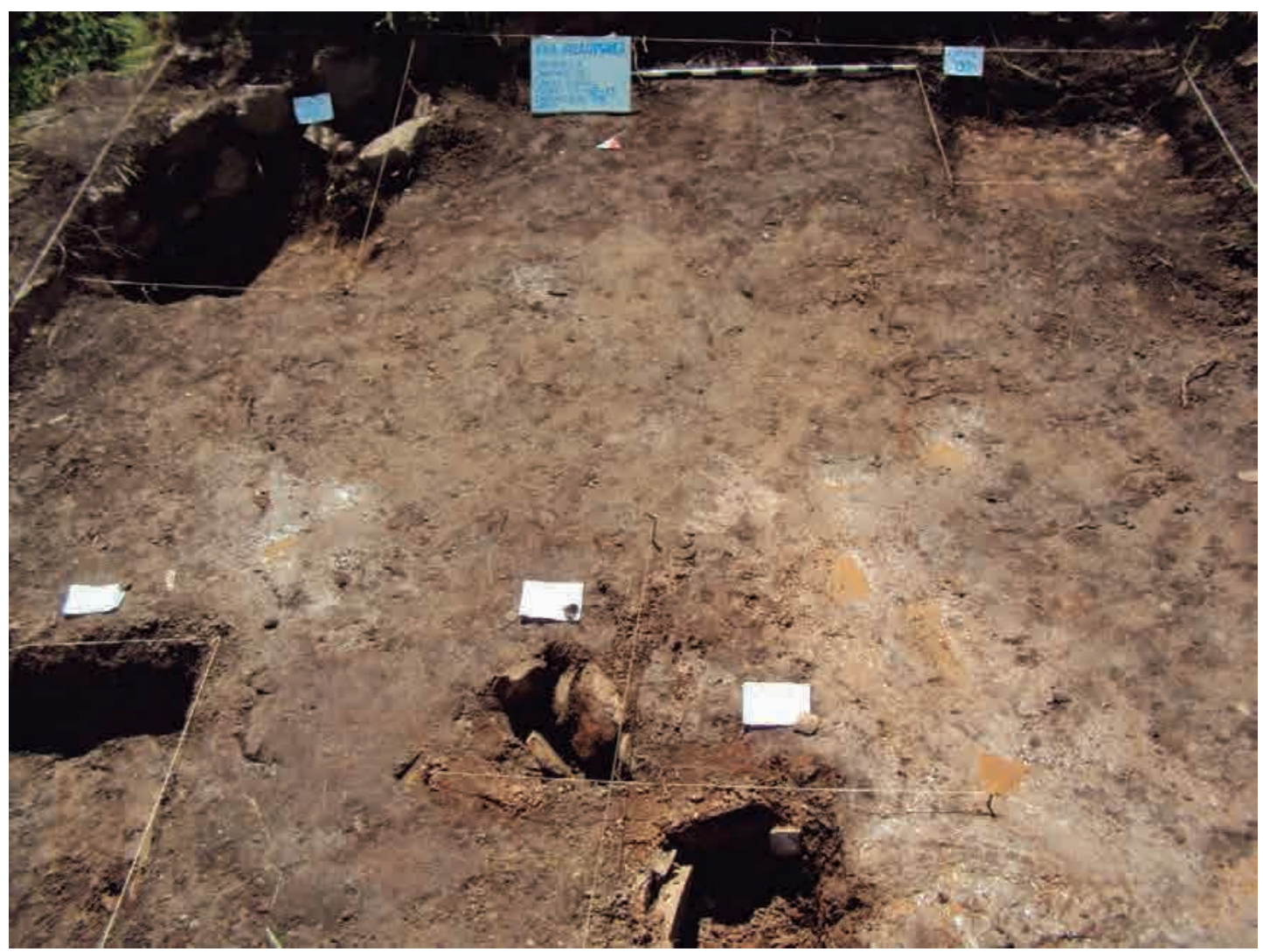

Figura 11: Unidad 2, vista del final de la unidad de excavación. 
UNIDAD 3: La unidad se emplazó tomando la mitad del interior del recinto rectangular de esquinas curvas (con un largo de $5.80 \mathrm{~m}$, un ancho de $4.30 \mathrm{~m}$ ), y la parte externa, asociada a un pasadizo. Tanto en el interior como en el exterior de la unidad se puede apreciar la misma secuencia estratigráfica; solo varia la proporción de cerámica local, ya que en el interior se apreciar una mayor cantidad.

Capa superficial: Capa de tierra de color negro y piedras angulosas medianas, cubierto de vegetación herbácea y arbustiva. Tiene un grosor de $0.03 \mathrm{~m}$ a $0.05 \mathrm{~m}$ Dentro de la unidad se aprecia un muro orientado hacia el norte.

Capa 1: Tierra de color gris de consistencia semi-compacta, piedras angulosas medianas. La superficie de la capa es irregular y discontinua. Se pudo identificar fragmentos de cerámica local de engobe negro en pequeñas proporciones. Al parecer estos fragmentos de cerámica local habrían sido parte de la argamasa del muro que se derrumbó.

Capa 2: Capa de tierra color negruzco de consistencia semi-compacta, piedras angulosas grandes y medianas; y algunas raíces de plantas. Tiene un grosor que varía de $0.16 \mathrm{~m}$ a $0.90 \mathrm{~m}$. En esta capa se halló fragmentos de cerámica local, Tawantinsuyu imperial y osamenta.

Capa final: Roca geológica de color rojizo amarillento de consistencia compacta.

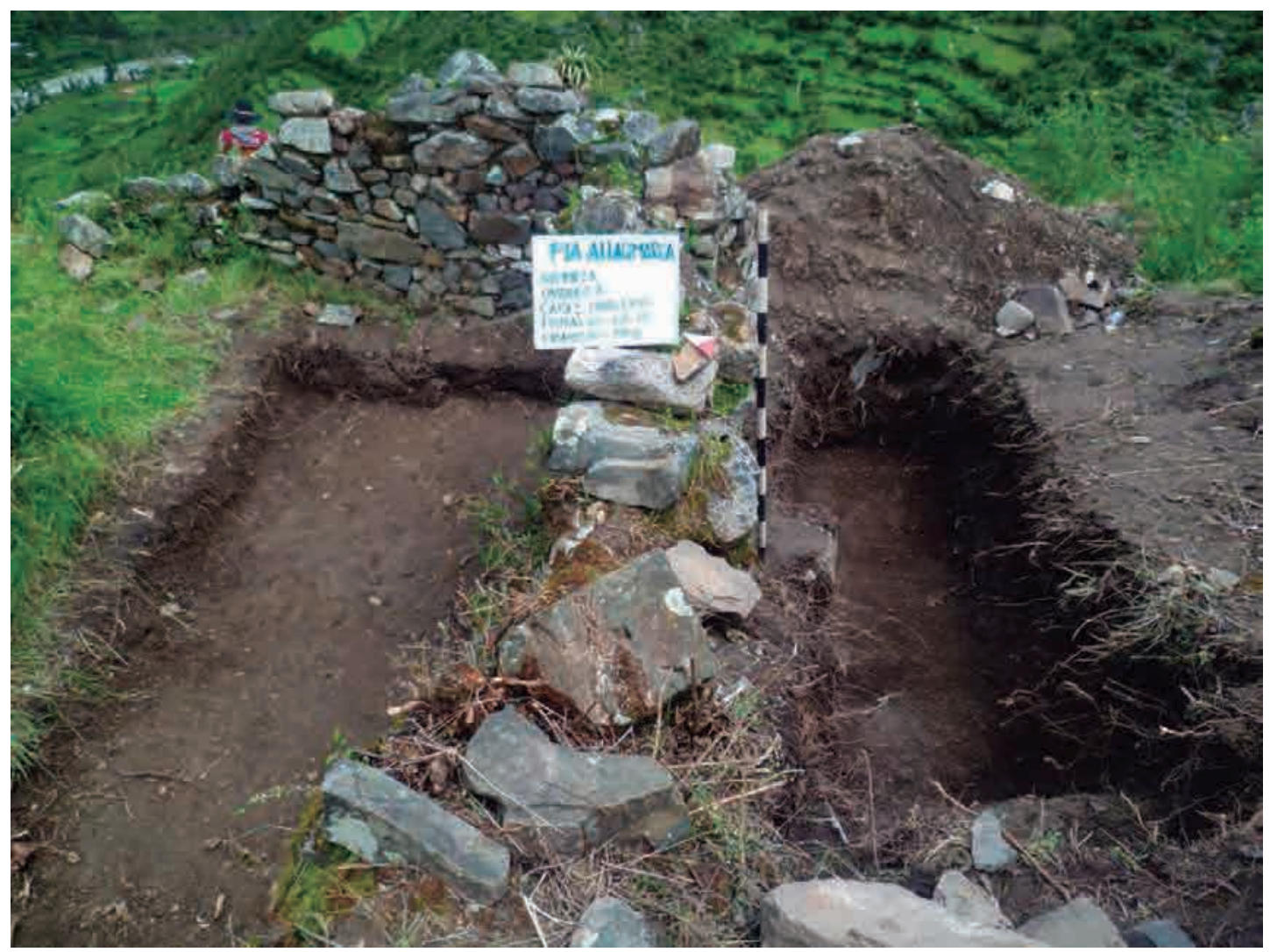

Figura 12: Unidad 3, vista del final de la unidad de excavación.

2.- Excavaciones en el sector B: En el sector B o sector medio se realizó la excavación de 5 unidades, las cuales fueron las siguientes: 
UNIDAD 4: Esta unidad se encuentra ubicada al interior de una kallanca Tawantinsuyu.

Capa superficial: Capa de tierra negra suelta con abundante vegetación arbustiva, con un grosor $0.02 \mathrm{~m}$. En superficie se halló fragmentos de cerámica y piedras angulosas. En esta capa se evidencio el hallazgo de una punta de proyectil de obsidiana (bifacial), asociado al muro $\mathrm{N}^{\circ} 2$ que se encuentra hacia el lado oeste del recinto, mezclado con tierra y piedras angulosas de derrumbe.

Capa 1: Capa de tierra de color plomizo, de consistencia suelta, con un grosor que varía de $0.10 \mathrm{~m}$. a $1.80 \mathrm{~m}$. Al interior de la capa se halló fragmentos de cerámica el estilo Tawantinsuyu regional e imperial, lascas de cuarzo, lascas de riolita, puntas de proyectil de obsidiana y óseos animal quemados; así como 3 morteros fragmentados, pulidores y un percutor.

Capa 2: Capa de tierra de color plomizo de consistencia semi-compacta,de un grosor que varía de 0.20m. a $0.23 \mathrm{~m}$. Se identificó fragmentos de cerámica Tawantinsuyu local e imperial; fragmentos de carbón, óseo y lítico. En esta capa se realizó el hallazgo de un tupo de cobre asociado al derrumbe del muro $n^{\circ} 3$ orientado hacia el norte.

Capa 3: Tierra de color beige de consistencia compacta. Presenta abundantes piedras angulosas de tamaño mediano y en menor proporción presenta cuarzo de tamaño pequeño. Al norte de esta unidad no se evidenció ningún material cultural mientras que al sur de la misma se encontró fragmentos de cerámica doméstica y fragmentos de cerámica Tawantinsuyu local. Además de ello se encontró óseo animal, carbón, lítico (pulidores), piruro de cerámica y tierra quemada.

Capa final: Roca geológica de color verdusco de consistencia compacta.
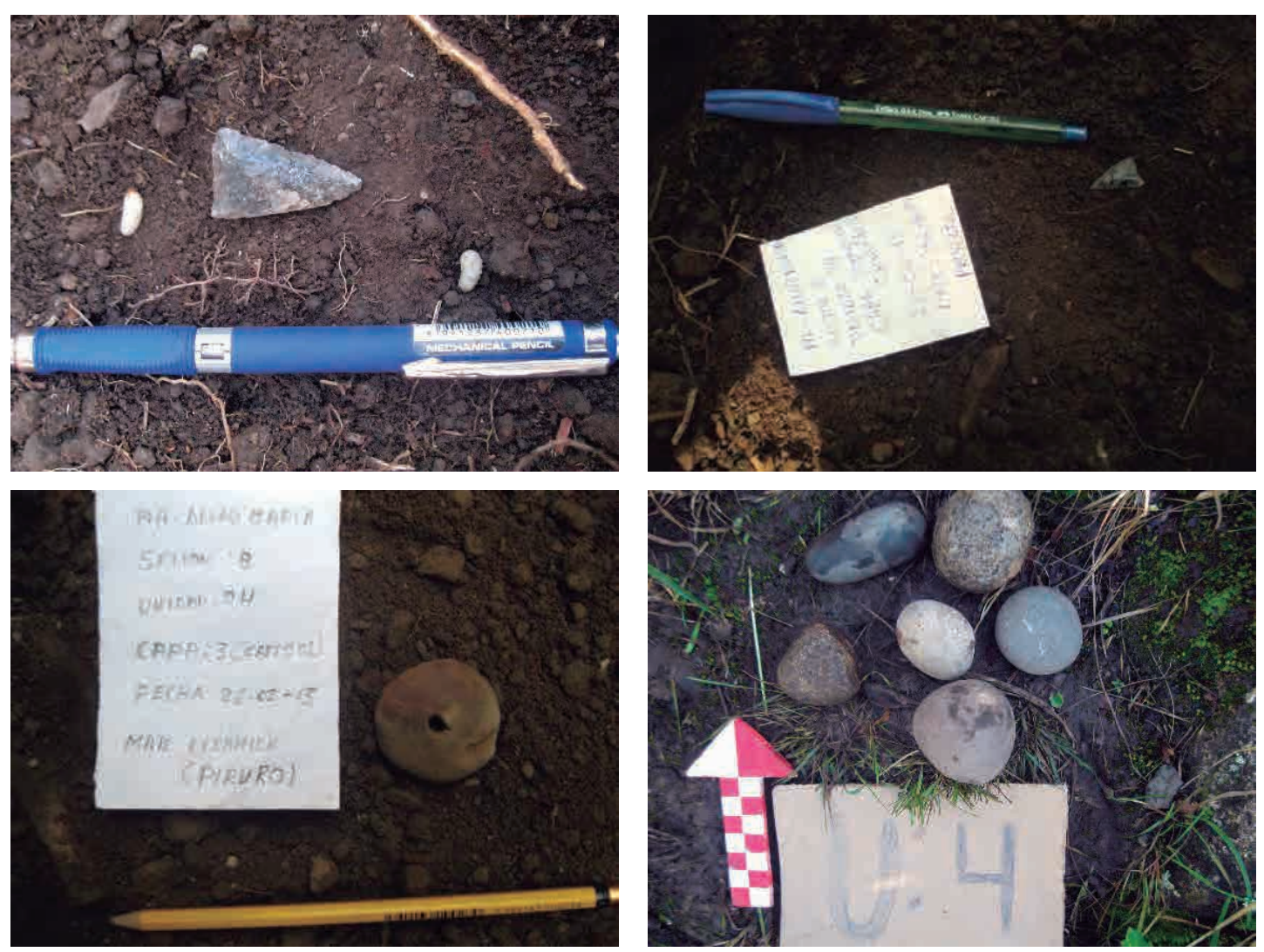

Figura 13: Vista de los hallazgos de la capa 1, unidad 4. 


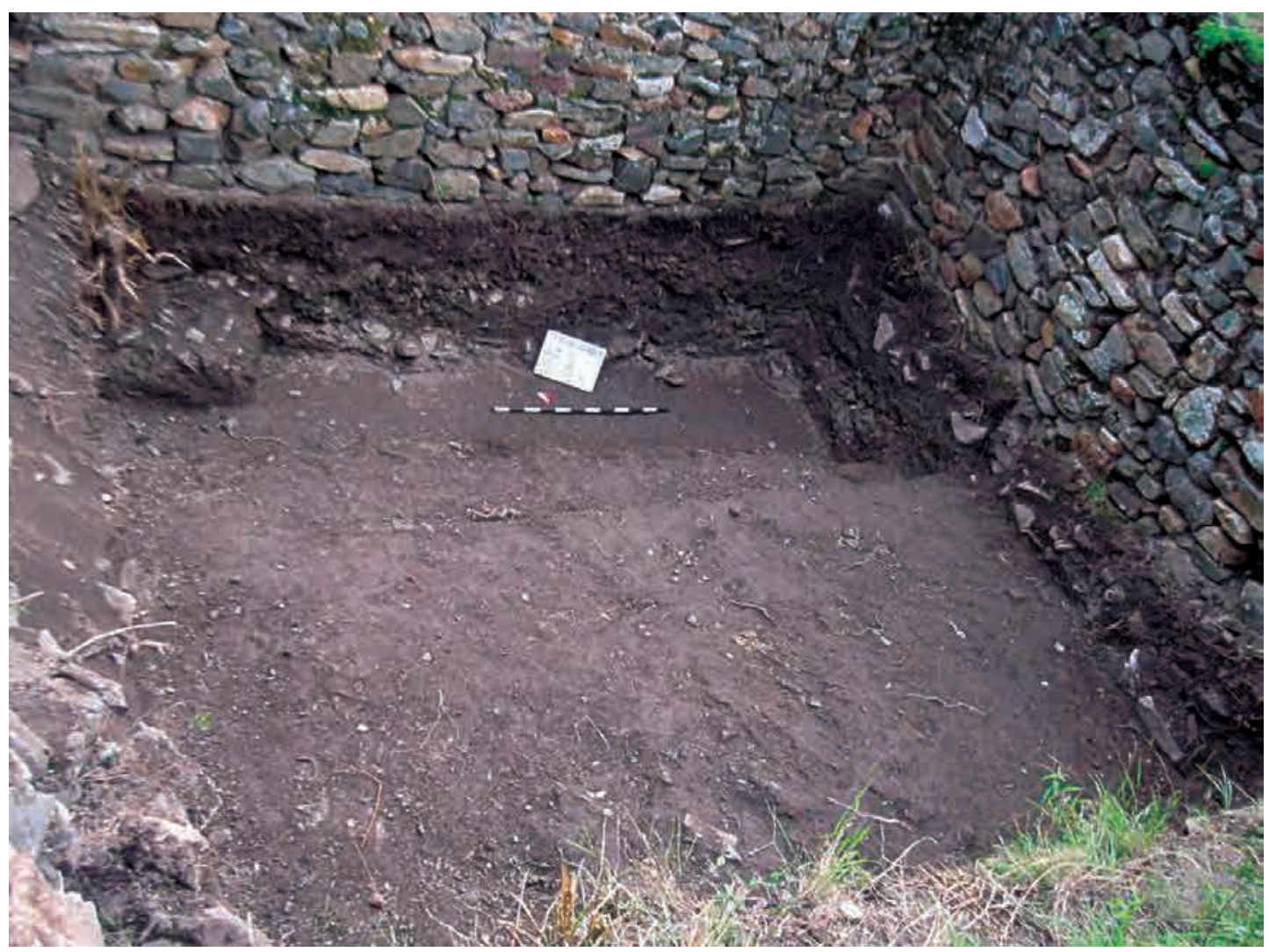

Figura 14: Vista del final de la excavación de la unidad 4.

La Kallanka es de planta rectangular $(11.00 \mathrm{~m}$. de largo, $6.40 \mathrm{~m}$. de ancho, $2.50 \mathrm{~m}$. de altura conservada y $0.55 \mathrm{~m}$. de ancho del muro), emplazado sobre una terraza. El material constructivo utilizado es piedra canteada y barro. Presenta un acceso de forma rectangular orientado hacia el este del recinto con una altura de $1.90 \mathrm{~m}$. y un ancho de $0.96 \mathrm{~m}$. Presenta 3 nichos cuadrangulares con dinteles ubicados hacia el lado sur del recinto (muro 3).

UNIDAD 5: Se emplazó al interior de un recinto de planta rectangular (Kallanka), en mal estado de conservación.

Capa superficial: Capa de tierra de color negro con abundante vegetación, de consistencia semicompacta, con un grosor que varía de $0.10 \mathrm{~m}$. a $0.60 \mathrm{~m}$. En el derrumbe del muro $\mathrm{N}^{\circ} 1$ (norte) y muro $\mathrm{N}^{\circ} 2$ (oeste) se halló material lítico (mano de mortero y batan) y fragmentaria de cerámica del estilo Tawantinsuyu imperial con motivos de helechos y bandas en rombos, asociados a cerámica local. Al interior del recinto se encontró la mayor cantidad de fragmentos de cerámica Tawantinsuyu y fuera de ella se encontró fragmentos de estilo local.

Capa 1: Capa de tierra de color gris de consistencia semi-compacta, de $0.10 \mathrm{~m}$. a $0.13 \mathrm{~m}$ de grosor. En esta capa se halló fragmentaría de cerámica (estilo local e Tawantinsuyu local) en pequeña proporción con engobe rojo y naranja; fragmentos de material óseo animal; carbón y escaso material lítico (mano de batan) y un fragmento de porra. Dentro del recinto cuadrangular se halló dos fogones en forma de "U" construida a base de piedras angulosas de una sola hilada. Al interior de estas se halló ceniza en gran cantidad. Al exterior del recinto rectangular se va identificando un muro semicircular. 
Capa 2: Capa de tierra de color beige de consistencia semi-compacta, de $0.15 \mathrm{~m}$ a 0.80m de grosor. Se halló abundantes fragmentos de material cerámico (estilo local y Tawantinsuyu local), material óseo humano y animal fragmentado, material lítico (mano de batanes, mano de morteros fragmentados y lascas de basalto).

Al norte del recinto (adherido al muro $\mathrm{N}^{\circ} 1$ ) se observa roca geológica de color beige. La proporción del material cultural cerámico (totalmente local) fuera del recinto y asociado al muro semicircular (muro $\mathrm{N}^{\circ} 5$ ) es mayor en relación al interior del recinto. En esta capa (2) se halló dos contextos funerarios:

Contexto funerario 1: Se ubicó al sur- este de la unidad, a -1.44 m. de la cota, asociado a los muros 5 y 6. Se trata del entierro secundario de un individuo masculino adulto (de 18 años aprox), presenta una cista de planta trapezoidal (de $1.10 \mathrm{~m}$ de largo por $0.50 \mathrm{~m}$ de ancho y $0.15 \mathrm{~m}$ de profundidad), elaborada a base de cantos rodados y lajas de piedras unidas con argamasa. Los objetos asociados son fragmentos cerámicos local y óseo de camélido.

Contexto funerario 2: Se ubicó al sur- este de la unidad, a -1.44 m. del cota. Se trata del entierro secundario de un individuo de edad no definida, colocado al interior de una cista de planta semicircular elaborada a base de cantos rodados y lajas de piedras unidas con argamasa. El diámetro de la matriz es de $0.80 \mathrm{~m}$., y $0.24 \mathrm{~m}$. de profundidad. Entre los materiales asociados se encuentran fragmentos de cerámica, material óseo, un asta de taruca y una mano de mortero.

El recinto ( ${ }^{\circ} 4$ - A) es de planta en "D" (de $9.30 \mathrm{~m}$ de largo, $6.20 \mathrm{~m}$ de ancho, una altura conservada del muro es de $1.65 \mathrm{~m}$. y muros de entre $0.40 \mathrm{~m}$ a $0.60 \mathrm{~m}$ de ancho), edificado a base de piedras canteadas unidas con argamasa, emplazado sobre una terraza.

El recinto $\left(\mathrm{N}^{\circ} 4-\mathrm{B}\right)$ es de planta semicircular, está emplazado debajo de las bases del recinto rectangular, sobre la terraza. El material constructivo utilizado es piedra canteada, unida con argamasa. Al interior del recinto se halló una escalinata ubicada en la esquina del mismo entre los muros 5 y 7. En la esquina comprendida entre los muros $\mathrm{N}^{\circ} 5$ y $\mathrm{N}^{\circ} 6$ se encontró dos cistas.
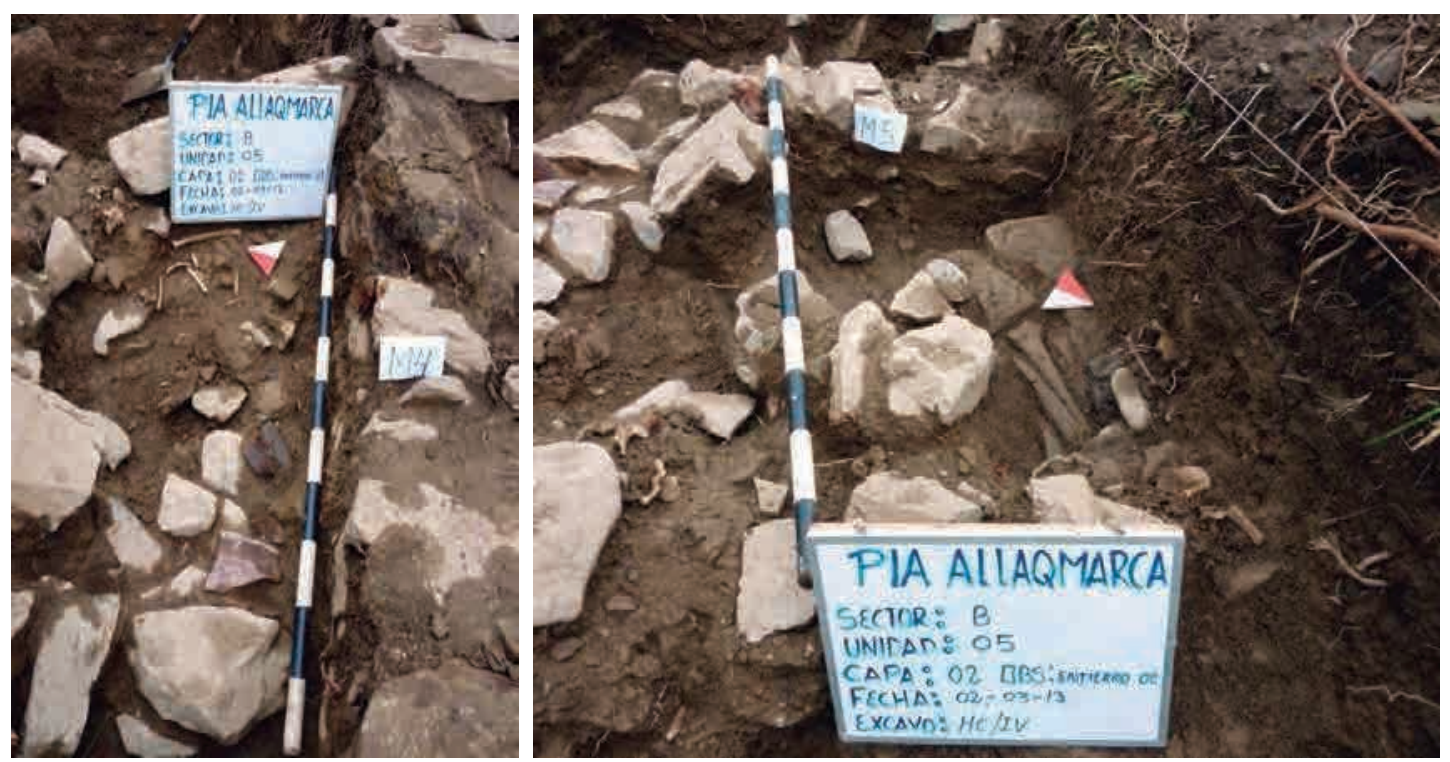

Figuras 15 y 16: Vista de los contextos funerarios 1 (izquierda) y 2 (derecha), unidad 5. 


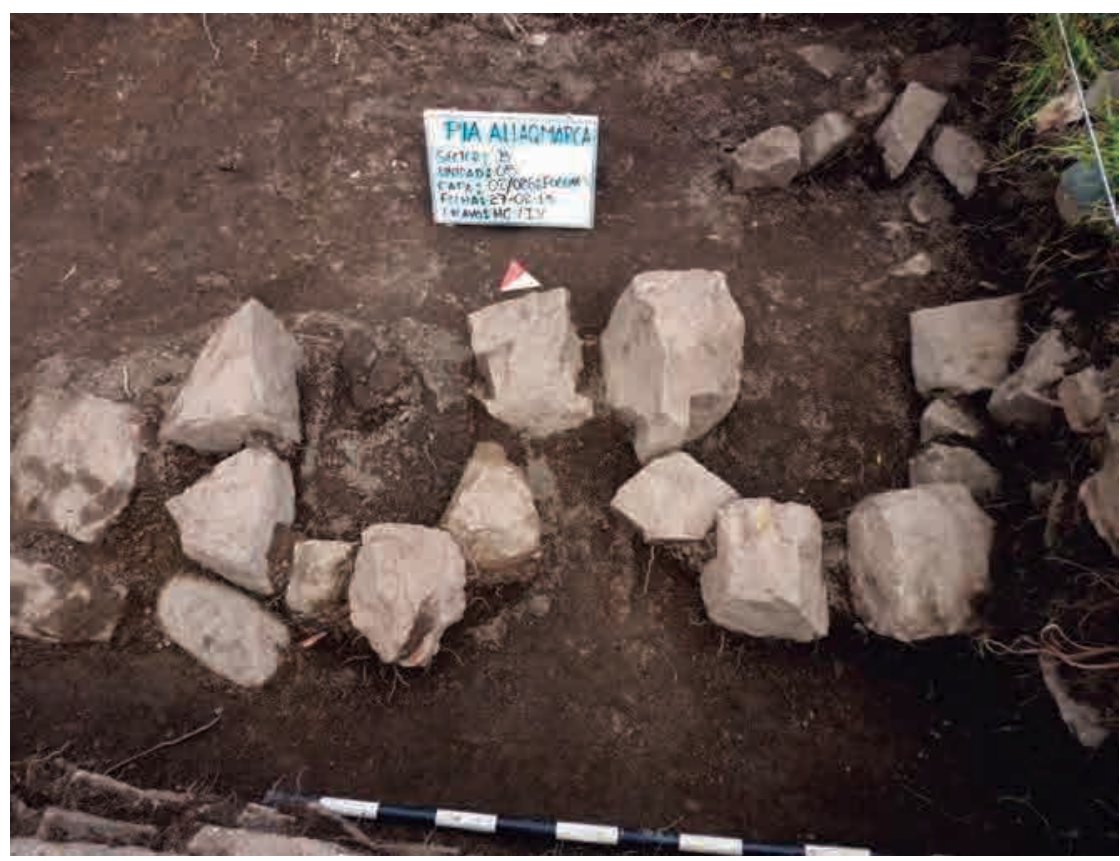

Figura 17: Vista de dos fogones en la capa 2, unidad de excavación 5.

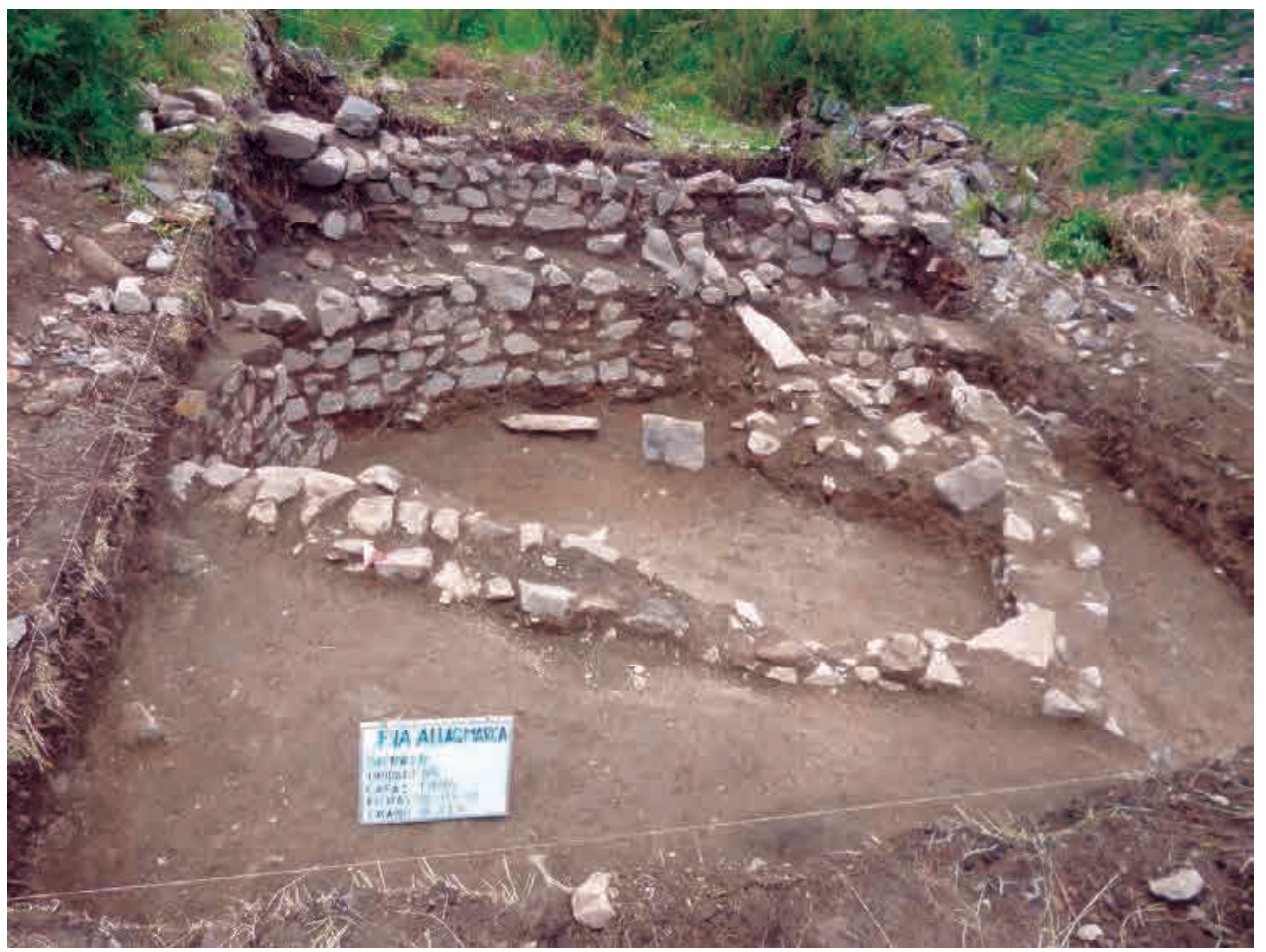

Figura 18: Vista final de la unidad de excavación 5, con la vista del recinto en "D". 
UNIDAD 6: Se excavó al interior de un recinto de planta rectangular (Kallanka de un largo de $12.00 \mathrm{~m}$., un ancho de $5.20 \mathrm{~m}$., altura conservada de $2.70 \mathrm{~m}$.), edificado a base de piedras canteadas, con un vano de acceso al sur-este del recinto. El recinto presenta las siguientes dimensiones: y un ancho del muro de $0.80 \mathrm{~m}$. Se encontró 5 nichos alineados en eje horizontal, asociados al muro 1 (suroeste).

Capa superficial: Capa de tierra color marrón de consistencia semi-compacta, con un grosor de 0.50 m., cubierta de vegetación arbustiva y herbácea. En esta capa se halló fragmentos de cerámica (Tawantinsuyu local) en poca cantidad, un batan y 4 morteros de mano, así como piedras canteadas derrumbadas de los muros.

Capa 1: Tierra de color marrón oscuro,semi-compacta, presenta un grosor de $0.10 \mathrm{~m}$., hallándose en su interior en mayor proporción fragmentos de cerámica del estilo Tawantinsuyu local y menor proporción material lítico (percutor, lámina de basalto y lascas de obsidiana) y material óseo.

Capa 2: Tierra de color beige de consistencia semi-compacta, con un grosor de $0.09 \mathrm{~m}$. En esta capa se halló fragmentos de cerámica de estilos locales y restos de material óseo en poca proporción. Además se encontró piedras canteadas y angulosas en forma discontinua y de manera irregular. Se excavó dos cateos de $0.25 \mathrm{~m}$ de profundidad sin hallar contexto alguno.

Capa final: Roca geológica de color rojizo amarillento de consistencia compacta.

UNIDAD 7: Se encuentra al interior del recinto $\mathrm{N}^{\circ} 1$ (Iglesia colonial). Construida a base de piedras canteadas y adobes superpuestos sobre una Kallanka Tawantinsuyu. Presenta un vano de acceso que se ubica hacia el este y un altar al interior del recinto en el lado sur. Tenía cubierta a dos aguas.

Capa superficial: Conformada por vegetación arbustiva, con un grosor $0.04 \mathrm{~m}$. En superficie se halló material lítico consistente en un pulidor y un mortero.

Capa 1: Tierra de color griss de consistencia compacta. Presenta un grosor máximo de $0.98 \mathrm{~m}$. y un mínimo de $0.75 \mathrm{~m}$.

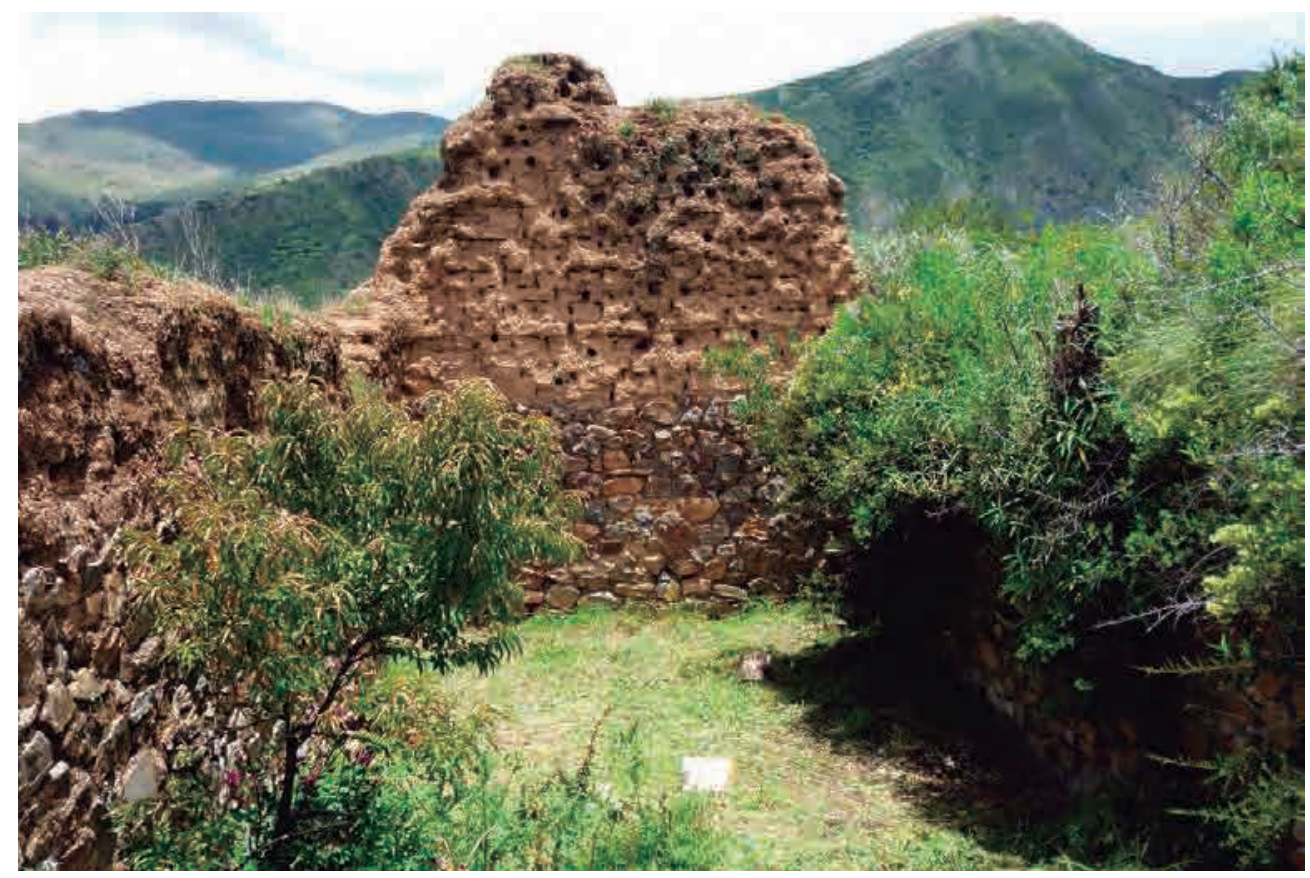

Figura 19: Vista del interior del recinto de la unidad 7, en la capa superficial. 
Capa 1: En esta capa se halló fragmentos de cerámica (local, Tawantinsuyu regional y colonial), material lítico (punta de proyectil y lascas de obsidiana y cuarzo), y dos contextos funerarios. Además se encontró carbón y tierra quemada en menor proporción. Además se halló un objeto de cobre disturbado elaborada por laminado (martillado).

Contexto funerario 1: Se trata de un neonato de 6-8 meses de edad asociado al muro 1 por el sur y a una hilera de piedras por el este. Se encuentra dentro de una pequeña cista de planta ovalada, elaborada a base de piedras angulosas, intrusivo a la capa geológica (arcilla). Sobre la cabeza del individuo se encontró colocada una piedra de forma trapezoidal de $0.20 \mathrm{~m}$ de longitud. La orientación del cuerpo es de norte a sur. Asociados a este entierro se encontró fragmentos de cerámica de estilo Tawantinsuyu local de engobe rojo. Este contexto es intrusivo y data del periodo colonial Temprano o de transición Tawantinsuyu - Colonial.

Contexto funerario 2: Se trata de un individuo adulto de 18 a 23 años de edad de sexo femenino asociado a una roca de $0.18 \mathrm{~m}$ de ancho; ubicado a una distancia de $2.20 \mathrm{~m}$ al noreste del muro 1 y a $2.25 \mathrm{~m}$ al sur del muro 3.Este individuo se encuentra dentro de una cista de planta ovalada elaborada a base de piedras angulosas de $0.28 \mathrm{~m}$ de profundidad, intrusivo a la capa geológica (arcilla). Sobre la cabeza del individuo se encontró colocada una piedra de $0.06 \mathrm{~m}$ de longitud. La orientación del cuerpo es de suroeste a noreste. Asociados al individuo se halló fragmentos de cerámica de engobe naranja y negro; y lascas de obsidiana.

Capa final: Roca geológica amarillenta de consistencia semi-compacta.

UNIDAD 12: Se emplazó en el interior de un recinto de planta rectangular de $4.88 \mathrm{~m}$ de largo por $3.05 \mathrm{~m}$ de ancho y una altura conservada de $0.98 \mathrm{~m}$.

Capa superficial: Tierra de color negro entremezclado convegetación herbácea y arbustiva, apreciándose la cabecera de un muro.

Capa 1: Tierra de color plomizo de consistencia semi-compacta. La superficie de esta capa es irregular y continua con un grosor de $0.55 \mathrm{~m}$. En esta capa se encontró fragmentos de cerámica doméstica de estilo local sin decoración y con engobe naranja y rojo; escaso material óseo animal; y lascas de obsidiana.

Capa 2: Tierra de color beige de consistencia semi-compacta. Esta capa es irregular y discontinua con un grosor de $0.35 \mathrm{~m}$. Además de material cerámico local se halló material óseo de camélido y lascas de obsidiana.

Capa final: Tierra arcillosa de color anaranjado de consistencia semi-compacta.

3.3 Excavaciones en el sector C: En el sector C o sector bajo se realizó la excavación de 4 unidades, de las cuales la Unidad 9 es la que mayor información nos ha brindado.

UNIDAD 9: Esta unidad se emplazó al interior de un recinto (Kallanka) de planta rectangular, edificado a base de piedras canteadas con argamasa.

Capa superficial: Conformada por vegetación y tierra de color negro. Presenta un grosor de 0.10 m. En superficie no se encontró ningún material cultural.

Capa 1: Tierra de color plomizo de consistencia semi-compacta, con un grosor máximo de $0.50 \mathrm{~m}$. En el interior de la capa se encontró fragmentos de cerámica del estilo Tawantinsuyu local, regional e imperial; material óseo animal (instrumento óseo) y material lítico (3 batanes fragmentados, 1 mortero y tres puntas de obsidiana).

Capa 2: Tierra de color plomizo claro de consistencia semi-compacta, de un grosor de $0.86 \mathrm{~m}$. En el interior de esta capa se encontró fragmentos de cerámica de estilo Tawantinsuyu local, material lítico (pulidor y puntas de obsidiana), material óseo trabajado, tupo de cobre y un piruro. 

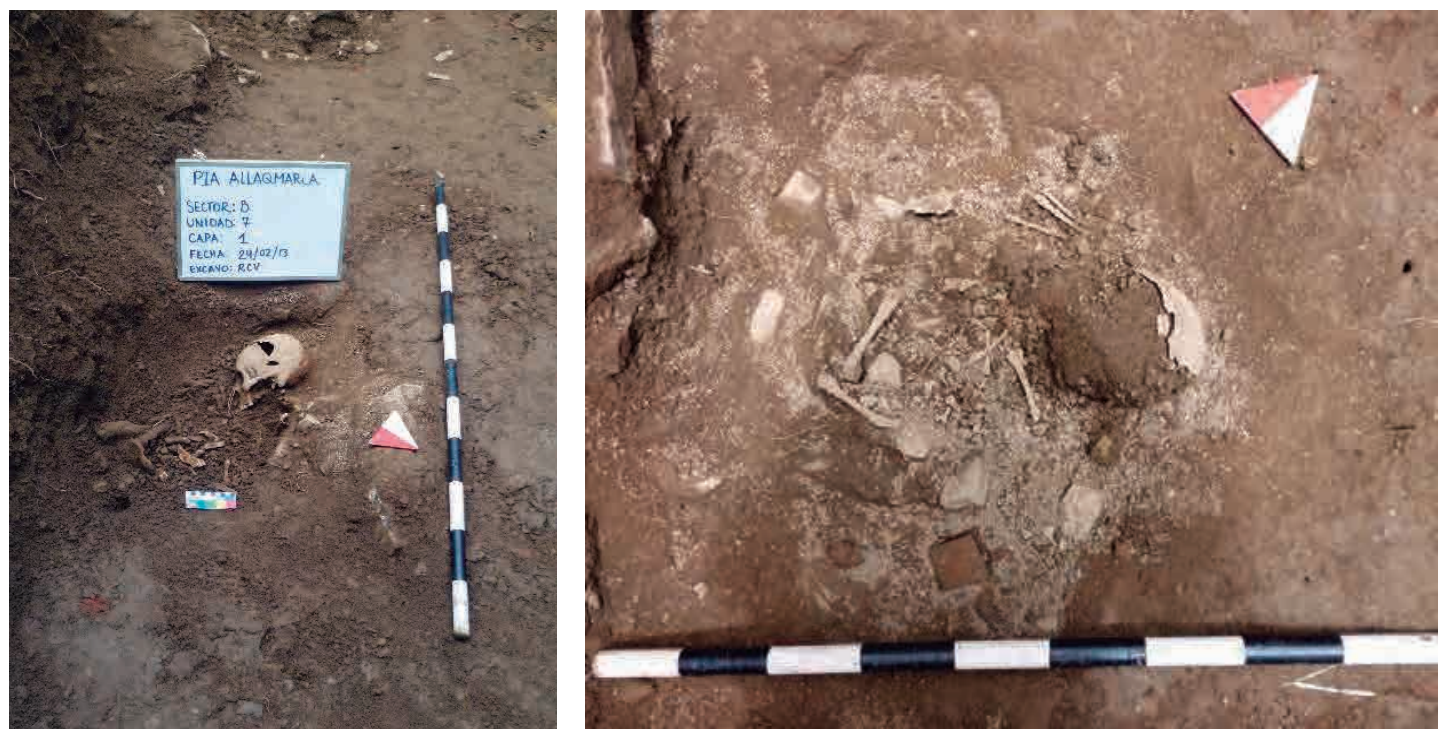

Figura 20 (izquierda): Vista del contexto funerario 2. Figura 21 (derecha): Contexto funerario 1, unidad de excavación 7.
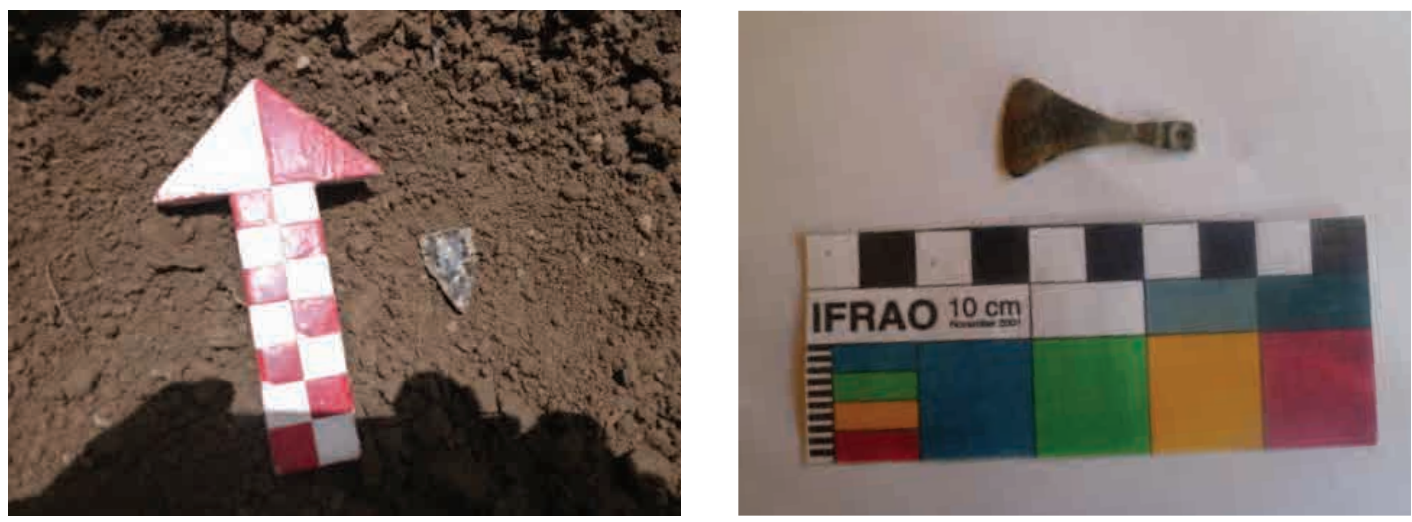

Figuras 22 y 23: Hallazgos de la capa 1, unidad 7. Punta de obsidiana (izquierda) y objeto de cobre (derecha).

Capa 3: Tierra de color beige de consistencia semi-compacta,de un grosor de $0.16 \mathrm{~m}$. En el interior de esta capa se encontró fragmentos de cerámica doméstica, material óseo animal trabajado, material lítico (punta de obsidiana y un percutor) y un piruro. Además se halló ceniza, tierra quemada y carbón.

\section{INTERPRETACIONES Y RESULTADOS}

A partir de la excavación de las 12 unidades de 4x4 m se logró identificar algunas de las características de la ocupación del sitio de Allaqmarca. Se trata de un sitio emplazado sobre un sector importante del extenso sistema de andenerías de Caraybamba. El cerro Allaqmarca de imponente forma piramidal que asciende desde el cauce mismo del río, tiene en la tercera parte superior el sitio del mismo nombre. Las excavaciones han permitido identificar tres periodos de ocupación: 

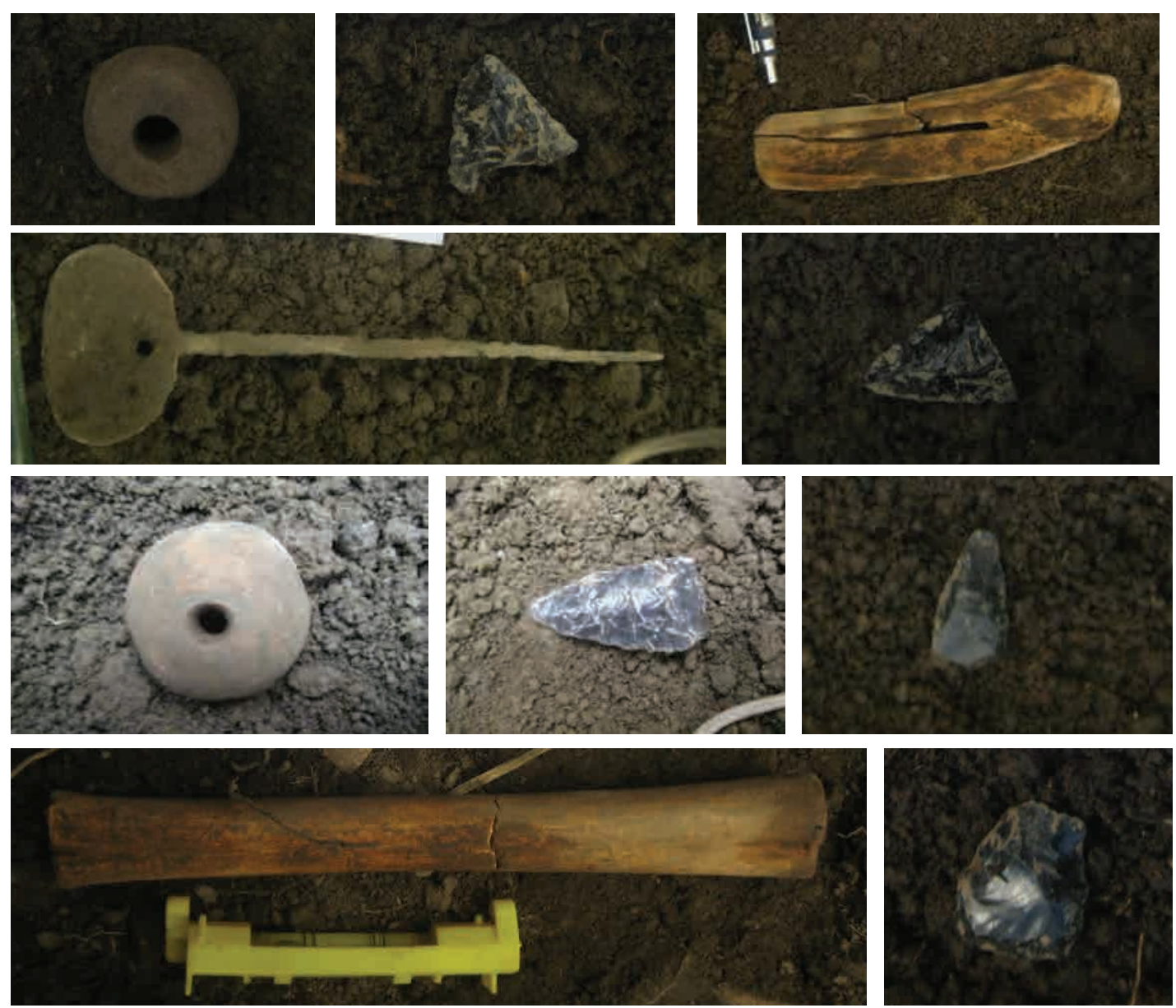

Figuras 24, 25, 26, 27, 28, 29, 30, 31, 32 y 33: Hallazgos de la unidad 9.

A.- Ocupación del Intermedio Tardío (1000-1450 d.c.): Correspondiente a las ocupaciones Aymaraes, caracterizadas por las edificaciones en planta ovalada o en "D", que en muchos casos se hallan debajo de las Kallankas del Horizonte Tardío, como en el caso de la unidad 7, con arquitectura a base de piedras canteadas unidas con argamasa. La cerámica asociada a este periodo es el estilo que hemos denominado como Estilo Caraybamba, de pasta naranja, con formas entre las que destacan: cántaros de cuello corto, platos, ollas de cuello corto, entre otros; con acabado de superficie pulido y alisado. Hacia los farallones laterales del cerro se aprecian contextos funerarios en estructuras tipo chullpa o en matrices simples cavadas en el cerro. Para este periodo los andenes ya están funcionando, edificados mediante la excavación del talud y relleno con suelos traídos de otros lugares del fondo del valle.

B.- Ocupación del Horizonte Tardío (1450 - 1533 d.c.): Corresponde al periodo en que el territorio de Caraybamba estuvo dentro del Tawantinsuyu. Se cambia la configuración espacial del sitio con la edificación de nuevos edificios y conjuntos arquitectónicos, como las Kallankas, de planta rectangular, que se edifican en grandes cantidades, muchas superpuestas a las edificaciones Aymaraes. Para este periodo se encuentra la cerámica de estilo Tawantinsuyu, en sus variedades: 
imperial, provincial y local, que coexiste en el sitio con el estilo Caraybamba, local. En la cima misma del cerro Allaqmarca, frente al apuMarka, se ha recuperado algunos contextos funerarios de neonatos, depositados mediante sacrificio y ofrenda ala divinidad local, acompañado de vasijas de estilo Tawantinsuyu local.

C.- Ocupación del periodo de Transición Tawantinsuyu - Colonial (1533 - 1570 d.c.): Abarca desde la llegada de los primeros invasores hispanos hasta la reducción de ayllus circundantes para la fundación del pueblo hispano de Caraybamba. En este periodo colonial temprano o de transición, la población sigue viviendo en sus pueblos originarios, sin embargo con fines de evangelización y control de la población, edifican nuevos edificios o remodelan kallankas, para que sirvan como parte del nuevo sistema administrativo y eclesiástico. Esto es lo que sucede con una kallanka que fue remodelada para que sirva como iglesia, edificando un altar. Sin embargo, el común de la población siguió desarrollando sus manifestaciones culturales propias, cosa que concluye con el traslado de la población para la fundación del pueblo hispano. Se ha encontrado además fragmentos de cerámica vidriada correspondiente a este periodo.

Con respecto a las kallankas, estas son características de las edificaciones del Tawantinsuyu. Eran las edificaciones más amplias, de planta rectangular, llegando a tener en el cusco o Huánuco Pampa hasta 70 metros de largo y con varias puertas de acceso laterales y en muchos casos múltiples ventanas y nichos en los muros laterales. Las Kallankas de Allaqmarca fueron áreas residenciales, tanto de la élite local como de los administradores cusqueños. Por ello se ha encontrado abundantes restos suntuarios, como puntas de obsidianas, cuchillos, tupus de cobre, prendedores, artefactos en huaso de camélidos, entre otros. La cantera de donde se obtenía la obsidiana estaba cerca al sitio por encima a una hora de camino.

\section{LOS MATERIALES CULTURALES DEL TAWANTINSUYU EN ALLAQMARCA}

\section{A.- La cerámica}

En cuanto a la cerámica del Horizonte tardío se ha encontrado ejemplares del tipo Inca Imperial, se hay identificado numerosos fragmentos edn el sitio de Allaqmarca, del tipo denominado por Bauer (Bauer 2002: 135) como Sillustani, por Rowe como Inca Provincial. Se trata de una cerámica con pintura crema, sobre la cual se delinean motivos decorativos en color marrón oscuro, muy similar a los tipos negro sobre blanco muy difundidos para el Intermedio Tardío en toda el área andina y que sería la continuación en etapa imperial del estilo Killque del Cusco preimperial, de similares características decorativas. La decoración de esta cerámica presenta elementos lineales, helechos o simplemente bandas horizontales alternadas con el fondo crema. Existen sin embargo algunos fragmentos de este tipo en los cuales el color marrón no delinea los motivos decorativos, sino el fondo, mientras que los motivos son representados por el color blanco de fondo. Se nota numerosos fragmentos con decoración en bandas horizontales en el gollete del arybalo, de gran grosor, dejando en medio de estas una delgada línea en color blanco, mientras en el cuerpo los motivos decorativos están representados por rombos concéntricos alternados en blanco y marrón. Según Alberto Bueno (comunicación personal) dataría del gobierno de Huayna Cápac, por su concepción e iconografía.

Se identificó también numerosos fragmentos del llamado Cusco Polícromo (Rowe 1944: figure XVIII), con decoración en bandas alternadas entre rojo, naranja y crema, delineadas estas con líneas de color negro y elementos decorativos lineales, geométricos y helechos en el interior de estos. Fragmentos con decoración lineal y helechos en color marrón o negro sobre fondo naranja claro, son muy comunes.

Se ha identificado además una gran cantidad de fragmentos de estilo Inca Local, los cuales se caracterizan por presentar formas arybaloides, aunque no bien definidas como las del Inca Imperial, 
con decoración similar a los motivos que presenta el Inca Imperial, pero elaborado en la misma región de Aymaraes, ya que la manufactura, la pasta y los componentes de la misma, son del lugar, similares al Estilo Caraybamba. Esta cerámica por lo general tiene pasta roja, cocción oxidante, y en muchos casos pasta gruesa y pintura roja total o parcial.
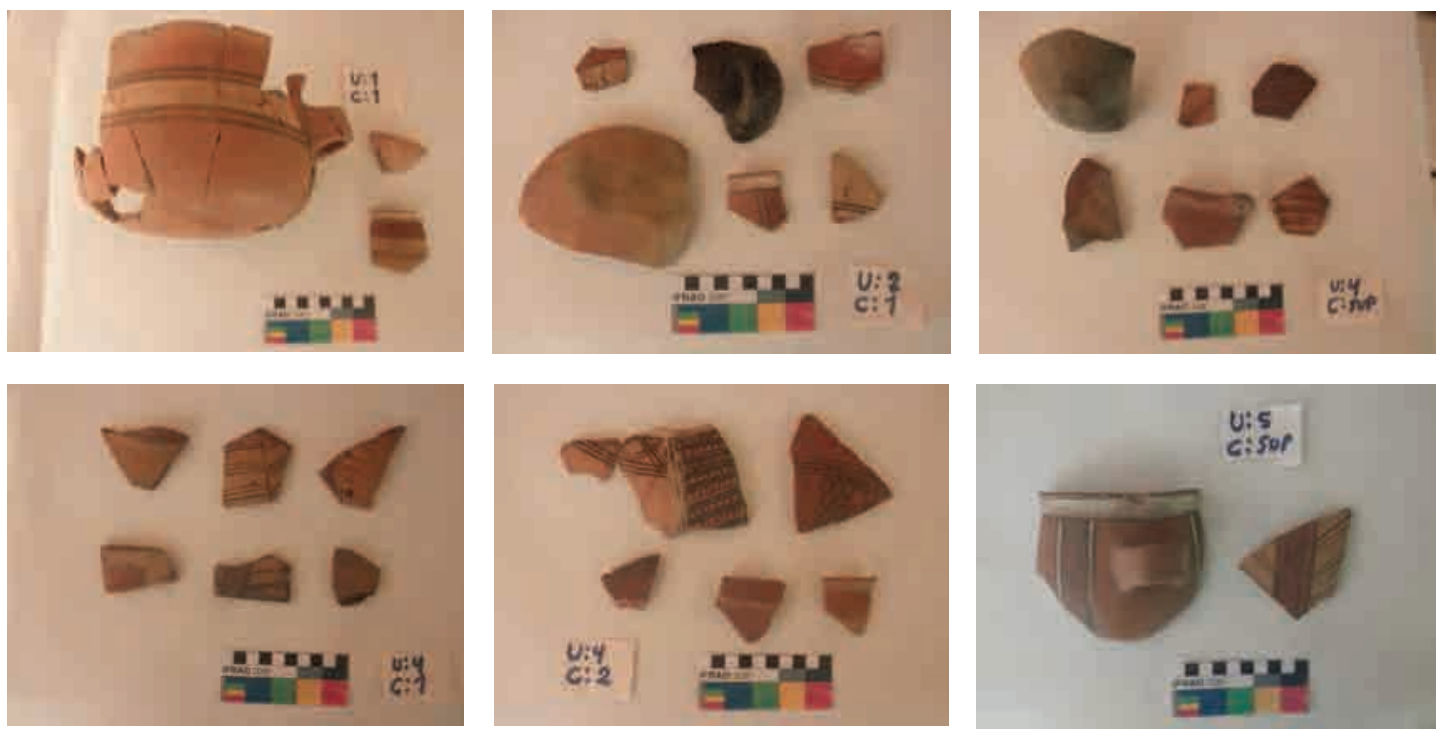

Figuras 34, 35, 36, 37, 38 y 39: Cerámica Tawantinsuyu recuperado de las excavaciones en Allaqmarca.
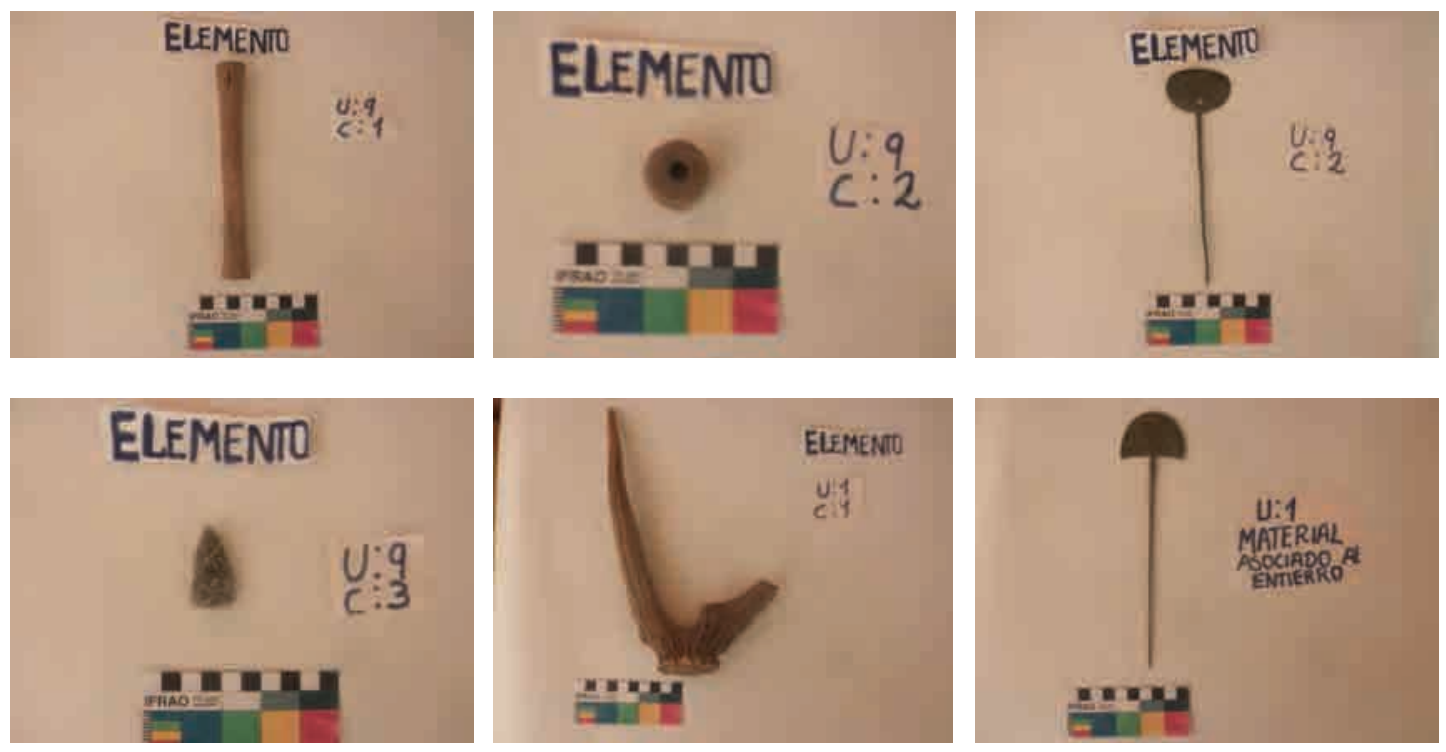

Figuras 40, 41, 42, 43, 44 y 45: Diversos tipos de materiales culturales del Tawantinsuyu recuperado de las excavaciones en Allaqmarca. 
Las formas corresponden a cántaros de gran tamaño, pasta gruesa y borde engrosado externo y ligeramente evertido; cántaros medianos de borde carenado y evertido; cántaros medianos de bordes evertidos y divergentes ligeramente cóncavos; ollas de cuello mediano y borde evertido; platos grandes y medianos. Estas vasijas presentan bases redondeadas, planas o ligeramente apuntadas. La mayoría presentan engobe rojo total, sobre la pasta naranja; mientras que otros presentan decoración lineal en color negro y en pocos casos marrón y blanco en bandas o líneas.

De igual manera se recuperó considerable cantidad de fragmentos pertenecientes al estilo Caraybamba (van Dalen 2011: 182-187), estilo local del Intermedio tardío que siguió fabricándose hasta el Tawantinsuyu.

\section{B.- Otros materiales culturales}

Se ha recuperado materiales de metal, la mayoría suntuosos y ornamentales, como es el caso de tupus, prendedores y otros. Estos objetos están elaborados de cobre y habrían sido elaborados en los alrededores del sitio de Allaqmarca. De igual manera llama la atención la cantidad de puntas y artefactos líticos recuperados, sobresaliendo los elaborados de obsidiana. De igual manera se han recuperado numerosos instrumentos productivos elaborados de hueso de camélido.

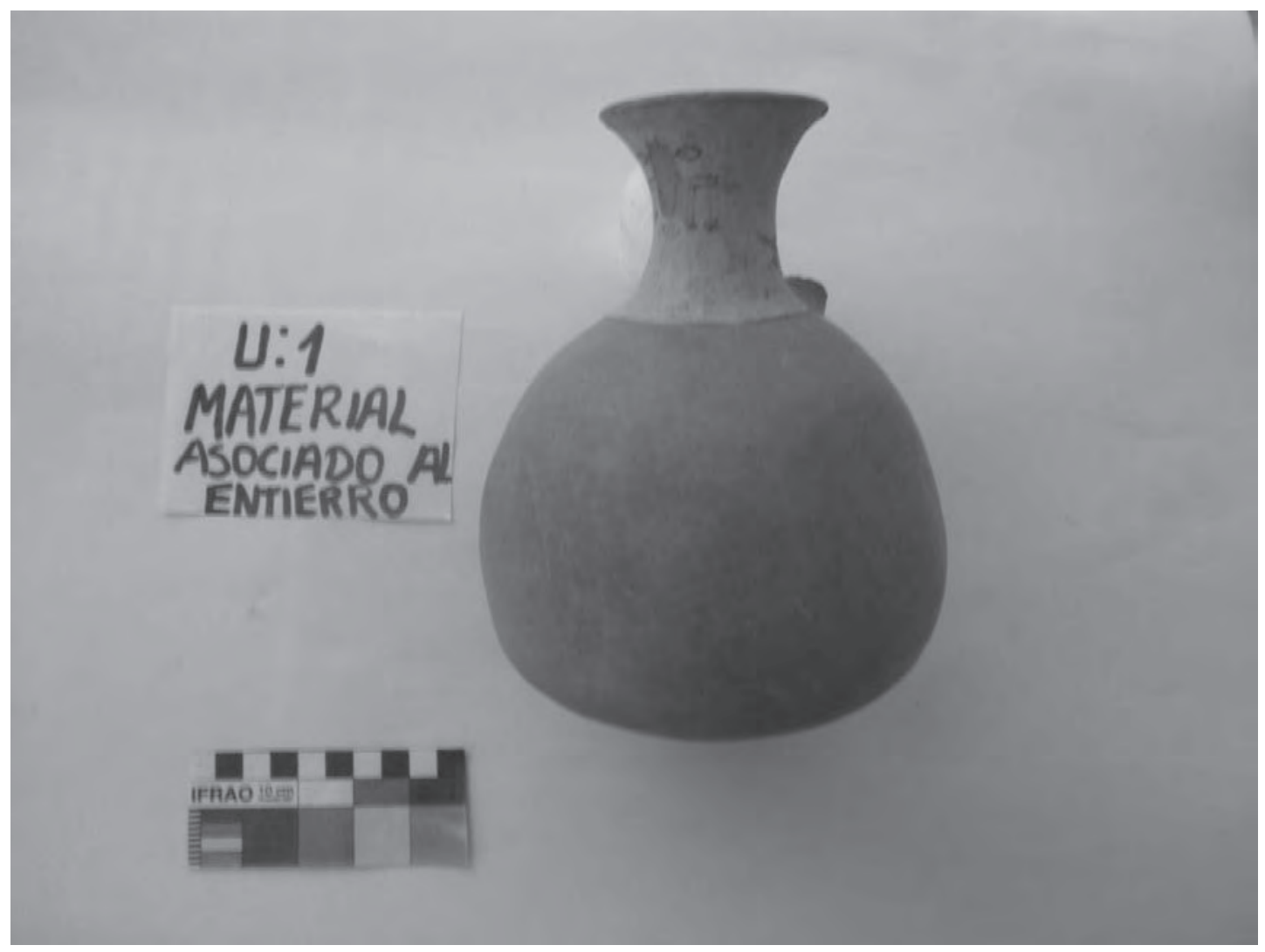

Figura 46: Vasija Tawantinsuyu asociado al contexto funerario de la unidad 1. 


\section{CONCLUSIONES}

Las excavaciones desarrolladas en el sitio arqueológico de Allaqmarca en Caraybamba durante la temporada 2013 reveló una densa ocupación durante el Tawantinsuyu, la cual se superpone a la ocupación Aymaraes del Intermedio tardío. Con la anexión del Tawantinsuyu, el sitio fue ampliado con la edificación de edificios tipo kallancas por toda la parte superior del cerro Allaqmarca, en algunos casos superponiéndose a antiguas construcciones Aymaraes de planta ovalada o en "D". El sistema de andenerías fue ampliado con la introducción de nuevas técnicas de construcción con gradería y relleno.

Con respecto a las excavaciones: El sector A, comprende las unidades: 1, 2 y 3, registra en las excavaciones evidencia de matrices en las dos primeras unidades, las cuales contenían contextos funerarios con osamenta humana en el interior, asociados a fragmentos y vasijas del estilo Tawantinsuyu Local (fragmentos o vasijas con formas del estilo Tawantinsuyu, pero de pasta y colores locales) e Imperial (con diseños geométricos, helechos y figuras del damero o conocido como diamantado); sin embargo también se aprecia fragmentos de cerámica de estilo Local-Caraybamba, cuyo engobe para el primer tipo se caracteriza por los colores naranja y rojo de pasta fina y acabado pulido; el segundo tipo de pasta negra para la vasijas utilitarias-domesticas, con presencia de hollín. Al parecer después de la llegada de los Incas a Allaqmarca, se continuó con las practicas locales en menor escala, con la convivencia paralela entre los locales y el Tawantinsuyu, por lo menos las prácticas cotidianas y en algunos casos los contextos funerarios demuestran la convivencia hasta el Horizonte Tardío, incluso la permanencia local se prolongaría hasta el periodo Colonial. Tanto en el interior y exterior de los recintos se pudo apreciar la misma correlación estratigráfica asociada a estos dos estilos de ceramios. En cuanto a la arquitectura local-doméstica, no hubo mayores modificaciones estructurales o inclusiones de elementos arquitectónicos Tawantinsuyu. La influencia Tawantinsuyu se manifiesta en los fragmentos hallados como parte del relleno cultural en las excavaciones y por las vasijas como elementos del contexto funerario, halladas en asociación con el individuo.

En el Sector B, se excavaron cinco unidades: 4, 5, 6, 7 y 12; las tres primeras unidades son Kallancas Tawantinsuyu instauradas tras la llegada de los Incas, en la cuarta unidad se puede apreciar una iglesia del Periodo Colonial Temprano, cuyas bases son piedras originarias de la cuarta Kallanca, la quinta unidad se emplazó en el interior de un recinto local del Intermedio Tardío. Los materiales recuperados de las excavaciones en las primeras capas provienen del derrumbe de los muros de las Kallancas, cuya argamasa contenía fragmentos de cerámica del estilo Tawantinsuyu Local, regional e imperial, además de material lítico como batanes, morteros y manos de moler que sirvieron como piedras para la construcción de las Kallancas, utilizadas en algunas partes del paramento; estos objetos líticos habrían sido reutilizados de los utensilios de las poblaciones locales, tras desarticular sus edificaciones principales. Secuencialmente las ocupaciones de estas unidades tienen tres momentos o periodos bien marcados. Desde un inicio poblaciones locales, la llegada de los Incas, hasta la invasión de los españoles y la imposición del cristianismo a través de las iglesias para extirpar las idolatrías. La edificación Colonial está representada por la iglesia, anterior a ello las dos primeras capas de las excavaciones que presentan material arqueológico de fragmentos de cerámica del estilo Tawantinsuyu, tanto local como regional e imperial, además de objetos como tupos, fragmentos de porras, etc. de manufactura imperial; anterior a ello ocupación autóctona, local, representada por esta cerámica monocroma, en algunos casos roja, naranja o negra. Esta ocupación local presenta fogones en forma de "U", recintos irregulares y entierros en pequeñas cistas. Otras de las peculiaridades son los lentes de ceniza y osamenta animal quemada al interior de los recintos, lo que supondría una habitación doméstica. Estas unidades también se caracterizaron por contener un número significativo de puntas de obsidiana, núcleos, lascas de cuarzo, lascas de riolita, morteros fragmentados, pulidores y percutores. 
Por último tenemos los entierros, tanto en el interior de los recintos como en los farallones orientados a la divinidad local: ApuMarka. El primer tipo de entierro estaba relacionado con los grupos locales del periodo Intermedio Tardío, con presencia de fragmentos de cerámica del estilo Caraybamba; mientras que el segundo tipo de entierro se da en el Horizonte Tardio como respuesta a la ritualidad de la cosmovisión Tawantinsuyu para enterrar personas muy próximo al ApuMarka, estos entierros presentan vasijas del estilo Tawantinsuyu regional y objetos asociados como tupos de manufactura Tawantinsuyu.

\section{RECONOCIMIENTOS Y AGRADECIMIENTOS}

El proyecto de Investigación Arqueológica Allaqmarca se ejecutó gracias al Vicerrectorado de Investigación de la Universidad Nacional Mayor de San Marcos, bajo la dirección del Vicerrector Dr. Bernardino Ramírez Bautista, como parte de los proyectos Multidisciplinarios de Investigación 2012, así como a la Municipalidad Distrital de Caraybamba, dirigido por su Alcalde Ing. Jacinto Taipe Huamaní. De igual manera un reconocimiento especial a los estudiantes de la Universidad Nacional Mayor de San Marcos que participaron durante los trabajos de campo: Rosario Castillo Valle, Luis Reymundo Lume, Wendy Flores Livia, Miguel Rodríguez Blas y Miler Malpartida Gamarra; así como a los estudiantes de la Universidad San Cristóbal de Huamanga: Henry Navarro Anyosa, Carina Paullo Mendoza, Iván Vivanco Ramos y Héctor Carhuas Tenorio. Así mismo a la encargada de Gabinete, Sonia Laurente Palomino. De igual manera un agradecimiento al presidente de la Comunidad Campesina de Caraybamba, Jorge Acho y a toda la población de Caraybamba por el apoyo prestado durante las investigaciones.

\section{BibliografíA}

AUCAHUASI DONGO, Rubén Dino

1966 Monografía de la Provincia de Aymaraes, departamento de Apurímac. Lima, 122 Pgs.

1989 "Cuenca del Apurímac: cuna del quechua y del aymara". En: Apurímac. Revista de actualidad, debate y desarrollo regional. № 5, Abancay, Pg. $24-25$.

BAUER, Brian

2002 Las antiguas tradiciones alfareras de la región del Cusco. Centro Bartolomé de las casas. Cusco, 264 pp.

BONAVIA, Duccio

1996 Los camélidos sudamericanos: una introducción a su estudio. Instituto Francés de Estudios Andinos, Universidad Peruana Cayetano Heredia. Lima, 843 Pgs.

COBO, Bernabé

1964 (1653) Historia del Nuevo Mundo. Biblioteca de Autores Españoles, tomo 91 y 92. Ediciones Atlas. Madrid.

DEL MAR DE LA TORRE, Humberto F.

1979 La Historia de Aymaraes y sus problemas. Chalhuanca, 269 Pgs.

GARCILAZO DE LA VEGA, Inca

1963 (1609) Los Comentarios reales de los Incas. Colección de autores de la Literatura Universal. Volumen IV. Montevideo, $462 \mathrm{Pp}$.

GONZALES CARRE, Enrique

1992 Los señoríos Chancas. Instituto de Estudios Andinos (INDEA), Universidad Nacional San Cristóbal de Huamanga. 153 Pgs.

MEDDENS, Frank; y VIVANCO POMACANCHARI, Cirilo

1998 "The Chanca Confederation: politicalmyth and archaeologicalreality" (Confederación Chanca: Mito político y realidad arqueológica, Traducción por Maria Elena Solier) 
ROWE, John H.

1944 An introduction to the archaeology of Cuzco. Papers of the Peabody Museum of American Archaeology and Ethnology. Vol. 27, N⒉ Harvard University. Cambridge.

SANTILLANA, Idilio

1999 “Andenes, canales y Paisaje” En: Los Incas. Arte y Símbolo. Colección Familiar Arte y Tesoros del Perú. Banco de Crédito. Lima, pg. 61-108.

TOLEDO, Francisco de

1975 Tasa de la visita General de Francisco Toledo. Introducción y versión paleográfica de Noble David Cook. Universidad Nacional Mayor de San Marcos. Dirección universitaria de Bibliotecas y Publicaciones. Lima.

VAN DALEN LUNA, Pieter D.

2007 "La recuperación de tecnologías prehispánicas como sistema de recuperación de la identidad nacional" Diario Yachay. № 10, julio. Lima, Pp. 9.

2009 "Andenerías y asentamientos Tardíos en Caraybamba, Apurímac". Investigaciones Sociales. Revista del Instituto de Investigaciones Histórico Sociales. Facultad de Ciencias Sociales. Universidad Nacional Mayor de San Marcos. № 22, Junio, Lima, Pp. 247-270.

2011 Arqueología prehispánica tardía de Caraybamba, Aymaraes, Apurímac. Asentamientos y Andenerías. Universidad Nacional Mayor de San Marcos. Lima, 265 pp. 



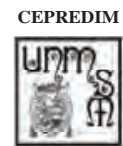

SE TERMINó DE IMPRIMIR EN EL MES DE NOVIEMBRE DE 2014

EN LOS TALLERES GRÁFICOS DEL

Centro de Producción Editorial e Imprenta de la Universidad Nacional Mayor de San Marcos Jr. Paruro 119, Lima 1.

Teléf.: 619-7000 AneXo 6009 / Fax: 1004, 6016

E-MAIL: ventas.cepredim.unmsm@gmail.com

PÁGINA WEB: Www.cepredim.com

Tiraje: 500 EJEMPLARES 